
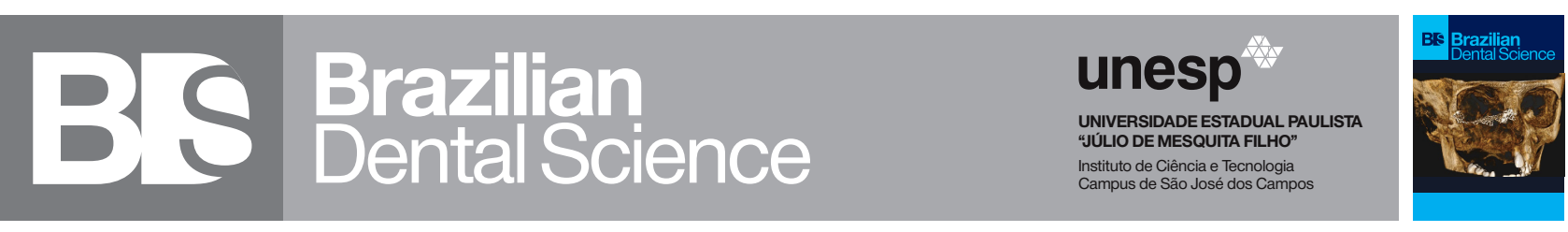

\title{
Antibacterial Efficacy of Conventional Versus Herbal Products on Streptococcus mutans in Adult Population- a Systematic Review \& Meta-analysis
}

Eficácia antibacteriana de produtos convencionais e fitoterápicos frente a Streptococcus mutans em adultos - uma revisão sistemática e meta-análise

Kavalipurapu Venkata TEJA ${ }^{1}$, Kaligotla Apoorva VASUNDHARA ${ }^{2}$, Gummuluri SRIRAM ${ }^{3}$

1 - Department of Conservative \& Endodontics, Saveetha Dental College, Chennai, India.

2 - Department of Prosthodontics \& Implantology - Sibar Institute of Dental Sciences - Guntur - India.

3 - SVS Group of Institutions - SVS School of Pharmacy - Bheemaram, Hanumakonda - Warangal - Telangana - India.

\section{ABSTRACT}

Background: Dental caries is challenging infectious disease, which is wide spread and difficult to control. Although it's multifactorial, microorganisms especially cariogenic Streptococcus mutans plays a wide role in initiation and progression of dental caries. Objective: The present review mainly aimed to evaluate and assess the antibacterial efficacy of herbal versus conventional products on Streptococcus mutans. Data Sources: A search was execute in electronic database (i.e., PUBMEDCENTRAL, COCHRANE, LILAC, SCIENCEDIRECT, GOOGLE SEARCH) using following search terms alone and in combination by means of PUBMED search builder from January 1990 up to July 2019. Study Eligibility Criteria: Studies were stipulate if they met the following criteria: In vivo studies comparing herbal and conventional products on anticariogenic or antibacterial activity on Streptococcus mutans were selected. Participants and Intervention: Adult patients aged from 18-65 years with dental caries undergoing intervention of herbal products. Study Appraisal and Synthesis Material and Methods: Out of 225 studies collected from databases, only 6 studies were included and other 6 were collected by hand search. Finally 12 included studies were analyzed out of which 5 studies were considered for meta-analysis. Results: The results unveil that natural

\section{RESUMO}

Introdução: A cárie dentária é um desafio para as doenças infecciosas, que são amplamente disseminadas e de difícil controle. Embora seja multifatorial, os microrganismos cariogênicos, em especial o Streptococcus mutans, desempenham um amplo papel na iniciação e progressão da cárie dentária. Objetivo: A presente revisão teve como objetivo principal avaliar a eficácia antibacteriana de produtos fitoterápicos em comparação com produtos convencionais frente a Streptococcus mutans. Os dados foram obtidos através de uma pesquisa executada em um banco de dados eletrônico (PUBMEDCENTRAL, COCHRANE, LILAC, SCIENCEDIRECT, GOOGLE SEARCH) usando termos isoladamente ou associados, por meio do construtor de pesquisa PUBMED, de janeiro de 1990 a julho de 2019. Foram selecionados estudos que atendessem aos seguintes critérios de elegibilidade: estudos in vivo comparando produtos à base de plantas e produtos convencionais sobre a atividade anticariogênica ou antibacteriana de Streptococcus mutans. Os participantes envolvidos consistiam de pacientes adultos de 18 a 65 anos com cárie dentária submetidos a intervenção de produtos fitoterápicos. Material e métodos: de 225 estudos coletados de bancos de dados eletrônicos, apenas 6 estudos foram incluídos e outros 6 foram selecionados por pesquisa manual. Finalmente, 12 estudos incluídos foram analisados, dos quais 5 foram considerados para meta-análise. Resultados: Os resultados revelaram que os 
products exerted virtually homogeneous antibacterial effect against Streptococcus mutans when compared with the counterpart. Limitations: Review was assessing on patients with dental caries and studies previously assessed did not mention about the caries risk. Prevalence varies based on caries risk assessments. Study was concentrating only on single species Streptococcus mutans. But ideally caries is multifactorial. Conclusion: Although natural products were effective, the present systematic review does not furnish concrete evidence to a show increased antibacterial efficacy of natural products as compared to conventional products.

\section{KEYWORDS}

Antibiotics; Chlorhexidine; Dental caries; Herbal; Streptococcus mutans. produtos naturais exerceram efeito antibacteriano homogêneo contra o Streptococcus mutans quando comparados com a contraparte. Limitações: A revisão avaliou pacientes com cárie dentária e os estudos prévios não mencionavam o risco de cárie. A prevalência varia com base nas avaliações de risco de cárie. $\mathrm{O}$ estudo se concentrou apenas em uma única espécie de Streptococcus mutans, mas a cárie dentária é de origem multifatorial. Conclusão: Embora os produtos naturais tenham sido eficazes, a presente revisão sistemática não fornece evidências concretas para mostrar um aumento da eficácia antibacteriana dos produtos naturais em comparação com os produtos convencionais.

\section{PALAVRAS-CHAVE}

Antibióticos; Clorexidina; Cárie dentária; Ervas, Streptococcus mutans.

\section{INTRODUCTION}

$\mathrm{D}$ ental caries is a dynamic phenomenon, resulting in the localized dissolution and destruction of dental hard tissues, by acidic byproducts, resulted from bacterial fermentation of carbohydrates [1]. Ecological plaque hypothesis states the important role of microbes as a key factor for dental caries causation [2]. Although caries is multifactorial, the main causative etiological factors include bacteria such as Streptococcus mutans and Lactobacillus [3].

Dental caries is ubiquitous in nature. It results from the interaction of the dietary constituents with the specific causative microbe [1]. Ideally, Plaque serves as a reservoir providing the homeostatic environment suitable for the destructive consequence [2]. Dental plaque transforms to a cariogenic plaque biofilm, once the bacteria tends to colonize on the surfaces of the substrate [2].

Streptococcus mutans are highly acidogenic and acid tolerant $[4,5,6]$. They serve as a key contributor for the caries progression [4]. These bacteria utilize the dietary sucrose, to synthesize the larger amounts of extracellular polysaccharides, followed by initial substrate adherence using glucan [4]. It is believed that, reducing the mass of Streptococcus mutans in the dental biofilm could lower the incidence of dental caries [7]. So, disengagement of Streptococcus mutans bacteria by usage of anti-adhesion agents without affecting their viability might serve as a valuable aid in clinically reducing the causative organisms at the root level [7].

Current caries combating strategies concentrate on usage of broad-spectrum antimicrobials for therapeutic advantage [8]. Although, they have a beneficial effect in short span, they impose bad impact on long run. Resistance of the microorganisms to antibiotics is the current issue that has to be addressed [9]. There is a growing evidence suggesting that the frequent usage of antibiotics induces resistance and threatens the effectiveness of the treatment $[9,10]$.

Literature favors a wide range of natural plant extracts exhibiting antimicrobial properties and therapeutic benefits $[11,12]$. Considering this fact, many clinicians have shifted their interest 
towards exploring the natural plant extracts [11]. Especially in dentistry, interest towards the usage of herbal products has increased.

Streptococcus mutans and Lactobacillus are the major microbes involved in the decalcification and tooth decay [13]. Ideally the caries combating strategies includes both mechanical and chemical plaque controlling methods, to prevent the disease progression [14]. So, basic mechanical plaque controlling methods alone may not be sufficient or effective to remove the cariogenic plaque. Adjunctive aids including chemical plaque controlling methods aid in better plaque removal [14].

So, considering all these facts, the present review was done to exploit and compare the benefits of various herbal formulations in reducing Streptococcus mutans levels in adult population.

\section{METHODS}

\section{Rationale of the Systematic review}

The aim of this systematic review was to assess the anti-bacterial effects of herbal products with the compared conventional product against Streptococcus mutans in adult population.

\section{OBJECTIVES}

The present systematic review included the articles published on both conventional versus herbal products used for management of caries associated bacteria. Search was carried out using multiple terms including various tooth-pastes and mouth washes from January 1990 to July 2019. This is a first ever study which concentrated on the clinical trials evaluated mainly the herbal and conventional tooth-pastes and mouthwashes on reducing the Streptococcus mutans levels in patients with dental caries.

\section{PICO Question}

Do herbal products bring about noteworthy antibacterial activity and reduction of Streptococcus mutans from saliva juxtapose to conventional products?

$$
\text { PICO Analysis }
$$
caries

- Population - Adult patients with dental

- Intervention - Herbal products

- Comparison - conventional products

- Outcome - Reduction in Streptococcus mutans

\section{Protocol for Registration:}

The present study was registered and reviewed by the ethical committee of institutional Ethical Committee prior to the start of the research.

\section{Eligibility Criteria:}

Types of Studies

Randomized clinical trials, comparative clinical trials, prospective clinical trials in which natural and conventional tooth-pastes and mouthwashes have been compared.

\section{Types of Participants}

Patients between 18-70 years of age with dental caries.

\section{Types of Interventions}

Herbal products and conventional products.

\section{Types of Outcome Measures}

Antibacterial efficacy against Streptococcus mutans.

\section{Exclusion Criteria}

The following studies were excluded,

- In vitro studies

- Animal studies

- Pediatric studies

- Review articles

\section{Information Sources}

For identification of studies included or considered for this review, detailed search strategies were developed for the database searched. The search was carried out from January 1990 to July 2019. All possible databases were searched and for precise selection of studies hand search were also carried out by the assessors involved in the search. 


\section{Searched Databases}

- PubMed

- PubMed Advanced Search

- SCIENCE DIRECT

- MEDLINE

- Google search

Language

Full text articles in English were only selected.

\section{Hand Search}

The following journals was hand searched

- Journal of Conservative dentistry

- Journal of dental research

- World Journal of Dentistry

- Journal of international society of preventive and community dentistry.

- Journal of operative dentistry and endodontics.

- Journal of Islamic dental association of IRAN.

- Journal of oral and maxillofacial pathology.

- Journal of Ayurveda and holistic medicine.

\section{SEARCH}

Search was carried out in electronic database (i.e., PUBMEDCENTRAL, COCHRANE, LILAC, SCIENCEDIRECT, and GOOGLE SEARCH) using following search terms alone and in combination by means of PUBMED search builder from January 1990 up to July 2019.

Various "search terms" or "key words" were used to execute the pubmed search. The searched terms were: "Dental decay", "Dental caries", "Human teeth", "enamel caries", "dentinal caries", "proximal caries", "cervical caries", "enamel caries", "acute caries", "mouthwashes and tooth pastes" including various herbal and conventional products such as: "acacia nilotica", "chitosan", "ginger", "baboon", babool", "tulsi", "blood root", "shiitake mushroom", "Punica granatum", "pomegranate", "pomegranate peel extract", "emblica officinalis", "terminalia chebula", "triphala", "licorice", "camellia sinensis", "oolong tea", "black tea", "green tea", "azadiracta Indica", "propolis", "neem", "garlic", "cacao bean extract", "cranberry", "natural products", "herbal", "plant extracts", "conventional products", " $0.2 \%$ chlorhexidine, "polyvinyl pyrrolidine", "anti-inflammatory", "0.12\% chlorhexidine", "analgesic", "benzocaine", "chlorhexidine", "0.2\% chlorhexidine", "cetylpyridinium chloride", "triclosan", "betadine", "xylitol", "flouride", "sodium flouride", "0.5\% sodium flouride", "antimicrobial", "antibacterial", "anticariogenic", "colony count", "colony forming units", "S.mutans", "Streptococcus mutans", "Streptococcus mutans reduction", "microbial count", "invivo", "clinical trial", "randomised clinical trial", "randomised controlled clinical trial", "clinical study", "invivo study".

Variables of interest (Table I) of the present systematic review were to assess the antimicrobial efficacy and anticariogenic activity of herbal agents against conventional agents on Streptococcus mutans in adult population.

Table I - Variables of Interest.

\begin{tabular}{|c|c|}
\hline S.No & Variables of Interest \\
\hline 1 & Antibacterial efficacy and anticariogenic activity \\
\hline
\end{tabular}

\section{Study Selection}

The search identified 258 publications out of which 32 duplicates were removed and 200 were excluded after title search. 26 Full text articles were obtained for studies and evaluated. After evaluation, 13 were excluded (Table II) based on inclusion and exclusion criteria. Finally, 6 were included based on the aforesaid criteria. Following hand search, 6 articles were included as it satisfied the inclusion and exclusion criteria. Therefore, a total of 12 publications fulfilled all criteria for inclusion (Chart 1). The above analysis was done by two independent reviewers and incase of disagreement, consensus was reached after discussion with a third reviewer. 
Chart 1 - PRISMA Flowchart.

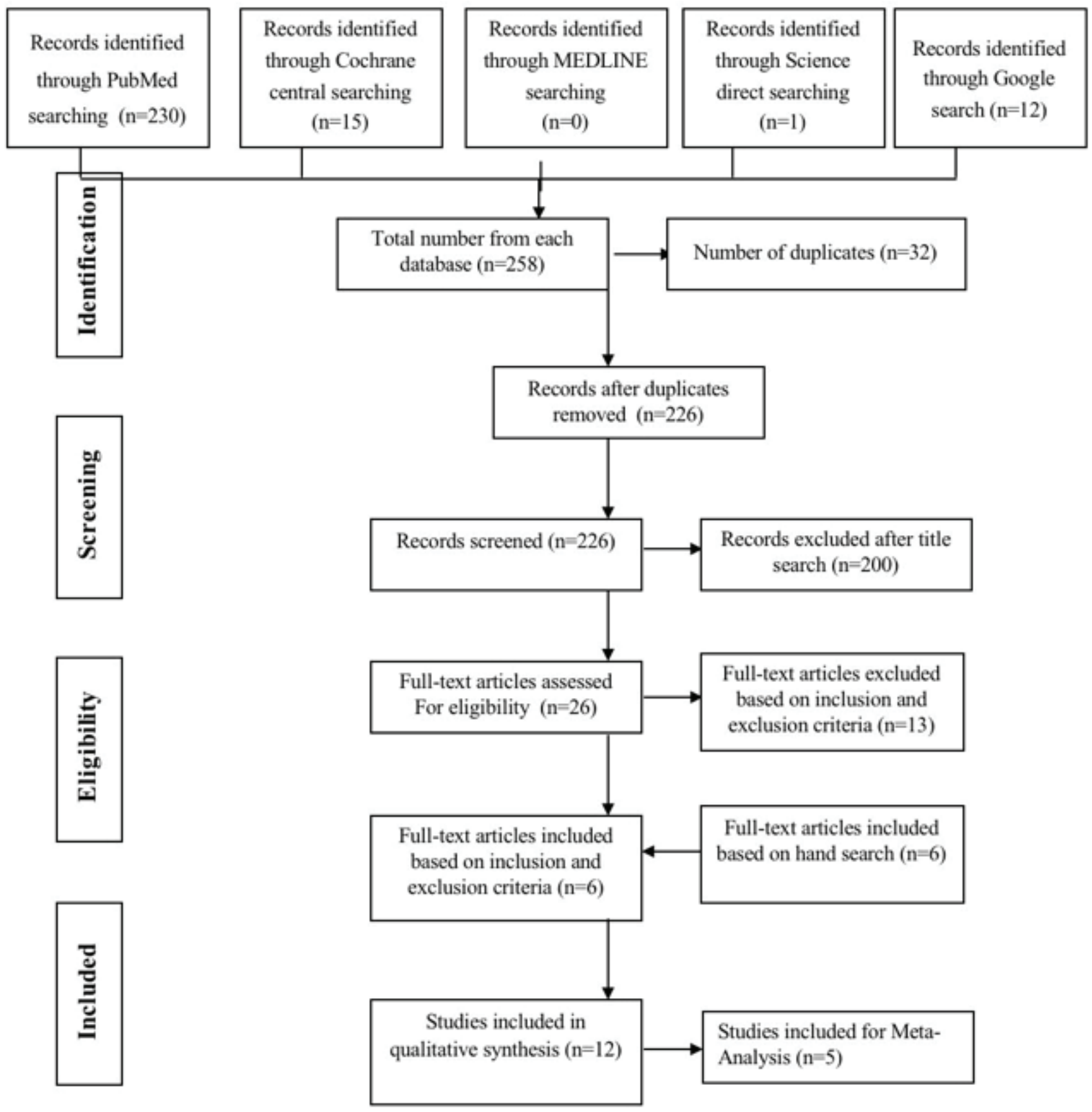


Table II - Charecteristics of Excluded Articles.

\begin{tabular}{|c|c|c|c|}
\hline S.No & AUTHOR & YEAR & $\begin{array}{l}\text { REASONFOR } \\
\text { EXCLUSION }\end{array}$ \\
\hline 1 & Mohankumar KP et al. [15] & 2013 & In vitro study \\
\hline 2 & Chatterjee A et al. [16] & 2017 & Irrelevant \\
\hline 3 & Namiranian H et al. [17] & 2012 & Irrelevant \\
\hline 4 & Megalaa N et al. [18] & 2018 & Irrelevant \\
\hline 5 & Nayak SS et al. [19] & 2012 & Irrelevant \\
\hline 6 & Agarwal Petal. [20] & 2011 & Irrelevant \\
\hline 7 & Hegde RJ et al. [21] & 2017 & Irrelevant \\
\hline 8 & Yoshihara A etal. [22] & 2001 & Irrelevant \\
\hline 9 & Malhotra N et al. [23] & 2001 & In vitro study \\
\hline 10 & Kulkarni VV et al. [24] & 2003 & Irrelevant \\
\hline 11 & Jauhari D et al. [25] & 2015 & Irrelevant \\
\hline 12 & Waly NG [26] & 1995 & Irrelevant \\
\hline 13 & Ullsfoss BN et al. [27] & 1994 & Irrelevant \\
\hline 2 & Chatterjee A et al. [16] & 2017 & Irrelevant \\
\hline
\end{tabular}

\section{Data Collection Process and Data Items}

The quality assessment of included trails was undertaken independently as a part of data extraction process, where assessment was based on four main quality criteria, which included: method of randomization, allocation concealment, outcome assessor blinding and completeness of follow up. Other methodological criteria included presence or absence of sample size calculation, comparability of groups at the start, clear inclusion and exclusion criteria.

\section{Risk of Bias of Individual Studies}

Risks of bias of included studies were assessed using Cochrane Risk of Bias assessment tool based on major and minor assessment criteria's. No risk of bias across the studies included in the present systematic review.

\section{Analysis \\ Synthesis of Results \& Additional}

Among the 12 included studies, [7,2838] only five [7,30,32,36,37] were considered for meta-analysis. Only studies, which provided baseline and post-analysis data (Mean \& S.D), were only considered. Meta-analysis was not possible for the studies $[28,29,31,33,34,35,38]$ interpreted the Streptococcus mutans count in terms of percentage reduction.

\section{Risk of Bias in Included Studies}

The assessments for the four main methodological quality items are shown in table. The study was assessed to have a "High risk" of bias if it did not record a "Yes" in three or more of the four main categories, "Moderate" if two out of four categories did not record a "Yes", and "Low" if randomization assessor blinding and completeness of follow - up were considered adequate.

\section{RESULTS}

\section{Study Selection}

The purpose of this review is to evaluate the antibacterial efficacy of natural products versus conventional products against Streptococcus mutans (Table I).

The search identified 258 publications out of which 32 duplicates were removed and 200 were excluded after title search. 26 Full text articles were obtained for studies and evaluated. After evaluation, 13 were excluded (Table II) based on inclusion and exclusion criteria. Finally, 6 were included based on the aforesaid criteria. Following hand search, 6 articles were included as it satisfied the inclusion and exclusion criteria. Therefore, a total of 12 publications fulfilled all criteria for inclusion (Chart 1).

In the present systematic review, all 12 articles included were randomized controlled trials which compared the antibacterial efficacy of natural and conventional products by quantitative analysis using microbial culture method (Colony forming units) (Table III), (Table IV), (Table V). 
Table III - General Information of Selected Articles.

\begin{tabular}{|c|c|c|c|c|c|c|}
\hline S.No & Author & Year & $\begin{array}{l}\text { Study } \\
\text { Design }\end{array}$ & Sample Size & Techniques Used & $\begin{array}{l}\text { Method of } \\
\text { Evaluation }\end{array}$ \\
\hline 1 & $\begin{array}{l}\text { Khairnar MR } \\
\text { etal. [7] }\end{array}$ & 2015 & $\begin{array}{l}\text { In Vivo } \\
\text { study }\end{array}$ & $\begin{array}{c}\mathrm{N}=50 \\
\text { Group 1 }(\mathrm{n}=25)-\text { Chlorhexidine } \\
\text { Group 2 }(\mathrm{n}=25)-\text { Cranberry }\end{array}$ & $\begin{array}{l}\text { Quantitative analysis using } \\
\text { microbial culture method } \\
\text { (Colony forming units) }\end{array}$ & $\begin{array}{l}\text { Paired t-test for intra- } \\
\text { group comparison for } \\
\text { evaluation of Strepto- } \\
\text { coccus mutansCFU } \\
\text { count, unpaired t-test } \\
\text { for intergroup compa- } \\
\text { rison for difference in } \\
\text { reduction }\end{array}$ \\
\hline 2 & $\begin{array}{l}\text { Botelho MA } \\
\text { et al. [28] }\end{array}$ & 2009 & $\begin{array}{l}\text { In vivo } \\
\text { study }\end{array}$ & $\begin{array}{c}\mathrm{N}=55 \\
\text { Group } 1(\mathrm{n}=27)-\text { Essential oil } \\
\text { Group 2 }(\mathrm{n}=28)-0.12 \% \text { chlorhexidine }\end{array}$ & $\begin{array}{l}\text { Quantitative analysis using } \\
\text { microbial culture method } \\
\text { (Colony forming units) }\end{array}$ & $\begin{array}{l}\text { Fisher's exact test and } \\
\text { Mann-Whitney U-test, } \\
\text { Wilcoxon test }\end{array}$ \\
\hline 3 & $\begin{array}{l}\text { Srinagesh J } \\
\text { etal. [29] }\end{array}$ & 2011 & $\begin{array}{l}\text { In vivo } \\
\text { study }\end{array}$ & $\begin{array}{c}N=57 \\
\text { Group } 1(n=18)-6 \% \text { triphala } \\
\text { Group 2 }(n=19)-0.2 \% \text { chlorhexidine } \\
\text { Group 3 }(n=20)-\text { Plain water }\end{array}$ & $\begin{array}{l}\text { Quantitative analysis using } \\
\text { microbial culture method } \\
\text { (Colony forming units) }\end{array}$ & ANOVA, post hoc test \\
\hline 4 & $\begin{array}{l}\text { Srinagesh J } \\
\text { etal. [30] }\end{array}$ & 2012 & $\begin{array}{l}\text { In vivo } \\
\text { study }\end{array}$ & $\begin{array}{c}N=60 \\
\text { Group } 1(n=20)-6 \% \text { triphala } \\
\text { Group 2 }(n=20)-0.2 \% \text { chlorhexidine } \\
\text { Group 3 }(n=20)-\text { Plain water }\end{array}$ & $\begin{array}{l}\text { Quantitative analysis using } \\
\text { microbial culture method } \\
\text { (Colony forming units) }\end{array}$ & ANOVA, posthoc test \\
\hline 5 & $\begin{array}{l}\text { Velmurugan } \\
\text { Aetal.[31] }\end{array}$ & 2013 & $\begin{array}{l}\text { In Vivo } \\
\text { study }\end{array}$ & $\begin{array}{c}\mathrm{N}=45 \\
\text { Group } 1(\mathrm{n}=15)-20 \% \text { aqueous extract of T. chebula } \\
\text { Group 2 }(\mathrm{n}=15)-20 \% \text { aqueous extract of E. officinalis } \\
\text { Group 3 }(n=15)-0.2 \% \text { Chlorhexidine }\end{array}$ & $\begin{array}{l}\text { Quantitative analysis using } \\
\text { microbial culture method } \\
\text { (Colony forming units) }\end{array}$ & $\begin{array}{l}\text { One way } \\
\text { ANOVA, Post-hoc } \\
\text { Tukey test. }\end{array}$ \\
\hline 6 & $\begin{array}{l}\text { Sam JE etal. } \\
\text { [32] }\end{array}$ & 2016 & $\begin{array}{l}\text { In vivo } \\
\text { study }\end{array}$ & $\begin{array}{l}\mathrm{N}=100 \\
\text { Group 1 }(\mathrm{n}=25) \text { - fluoride tooth paste and mouth wash } \\
\text { Group 2 }(\mathrm{n}=25) \text { - chlorhexidine tooth paste and mouth wash } \\
\text { Group }(\mathrm{n}=25) \text { - herbal tooth paste and mouthwash( false } \\
\text { black, pepper, Indian gum Arabic, neem,pomegranate,tripha- } \\
\text { la) (Himalya complete care) } \\
\text { Group 4 (n=25)- xylitol tooth paste and mouthwash }\end{array}$ & $\begin{array}{l}\text { Quantative analysis using } \\
\text { commercial caries risk test } \\
\text { (CRT) }\end{array}$ & $\begin{array}{l}\text { Post-hoc with a bon- } \\
\text { ferroni test }\end{array}$ \\
\hline 7 & $\begin{array}{l}\text { Yadav M et } \\
\text { al. [33] }\end{array}$ & 2017 & $\begin{array}{l}\text { In vivo } \\
\text { study }\end{array}$ & $\begin{array}{c}\mathrm{N}=45 \\
\text { Group 1 }(n=15)-2 \% \text { Green coffee bean extract } \\
\text { Group 2 }(n=15)-0.2 \% \text { Chlorhexidine } \\
\text { Group 3 }(N=15) \text { - Sterile water }\end{array}$ & $\begin{array}{l}\text { Quantitative analysis using } \\
\text { microbial culture method } \\
\text { (Colony forming units) }\end{array}$ & $\begin{array}{l}\text { One-way ANOVA, } \\
\text { Paired t-test for intra- } \\
\text { group comparison, } \\
\text { Post-hoc test. }\end{array}$ \\
\hline 8 & $\begin{array}{l}\text { Usha Cetal. } \\
\text { [34] }\end{array}$ & 2017 & $\begin{array}{l}\text { In vivo } \\
\text { study }\end{array}$ & $\begin{array}{c}\mathrm{N}=46 \\
\text { Group 1 }(\mathrm{n}=23)-0.12 \% \text { chlorhexidine } \\
\text { Group 2 }(\mathrm{n}=23)-\text { Stevia mouthwash }\end{array}$ & $\begin{array}{l}\text { Quantitative analysis using } \\
\text { microbial culture method } \\
\text { (Colony forming units) }\end{array}$ & $\begin{array}{l}\text { Wilcoxon matched- } \\
\text {-pairs signed-rank test } \\
\text { for intergroup compa- } \\
\text { rison, Mann-Whitney } \\
\text { test for intragroup } \\
\text { comparison. }\end{array}$ \\
\hline 9 & $\begin{array}{c}\text { Biria M et al. } \\
\text { [35] }\end{array}$ & 2017 & $\begin{array}{l}\text { In vivo } \\
\text { study }\end{array}$ & $\begin{array}{c}\mathrm{N}=60 \\
\text { Group 1(n=30)-masdent tooth paste (pistacia lentiscus } \\
\text { extract) } \\
\text { Group 2 }(n=30) \text {-Crest complete tooth paste (Fluoride tooth } \\
\text { paste) }\end{array}$ & $\begin{array}{l}\text { Quantitative analysis using } \\
\text { microbial culture method } \\
\text { (Colony forming units) }\end{array}$ & $\begin{array}{l}\text { Mann Whitney U test } \\
\text { and Wilcoxon test }\end{array}$ \\
\hline 10 & $\begin{array}{l}\text { Vinod KS et } \\
\text { al. [36] }\end{array}$ & 2018 & $\begin{array}{l}\text { In vivo } \\
\text { study }\end{array}$ & $\begin{array}{c}\mathrm{N}=200 \\
\text { Group1(n=100)- } 0.12 \% \text { chlorhexidine } \\
\text { Group 2 }(\mathrm{n}=100) \text { - Formulated herbal mouthwash (tulsi,- } \\
\text { neem,triphala,turmeric) }\end{array}$ & $\begin{array}{l}\text { Quantitative analysis using } \\
\text { microbial culture method } \\
\text { (Colony forming units) }\end{array}$ & $\begin{array}{l}\text { Paired t test, ANOVA, } \\
\text { followed by Tukey's } \\
\text { posthoc test }\end{array}$ \\
\hline 11 & $\begin{array}{l}\text { Jeddy N et al. } \\
\text { [37] }\end{array}$ & 2018 & $\begin{array}{l}\text { In vivo } \\
\text { study }\end{array}$ & $\begin{array}{c}\mathrm{N}=60 \\
\text { Group 1(n=15)- Dr.Dental care liquid (red ginseng extract, } \\
\text { sweterica japonica, camellia sinensis, licorice) } \\
\text { Group 2 ( } n=15 \text { )- colgate plax mouth wash (cetylpyridium } \\
\text { chloride and sodium fluoride) } \\
\text { Group 3 }(n=15) \text { - Listerine mouth wash } \\
\text { Group } 4 \text { ( } n=15) \text { - Rexidine mouth wash ( } 0.2 \% \text { w/v chlorhexi- } \\
\text { dine) }\end{array}$ & $\begin{array}{l}\text { Quantitative analysis using } \\
\text { microbial culture method } \\
\text { (Colony forming units) }\end{array}$ & $\begin{array}{l}\text { Wilcoxon sign-rank } \\
\text { test }\end{array}$ \\
\hline 12 & $\begin{array}{l}\text { Aparna M et } \\
\text { al. [38] }\end{array}$ & 2018 & $\begin{array}{l}\text { Invivo } \\
\text { study }\end{array}$ & $\begin{array}{l}\text { Group } 1(n=25) \text { - Licorice mouth wash) } \\
\text { Group 2 }(n=25) \text { - triphala mouth wash } \\
\text { Group 3 }(n=25) \text { - chlorhexidine mouthwash }\end{array}$ & $\begin{array}{l}\text { Quantitative analysis using } \\
\text { microbial culture method } \\
\text { (Colony forming units) }\end{array}$ & Anova test \\
\hline
\end{tabular}


Table IV - general information of variables of interest and interpretation.

\begin{tabular}{|c|c|c|c|c|c|c|c|c|}
\hline S.No & $\begin{array}{l}\text { Author } \\
\text { \&Year }\end{array}$ & $\begin{array}{c}\text { Study } \\
\text { Type }\end{array}$ & $\begin{array}{l}\text { Study } \\
\text { Design }\end{array}$ & $\begin{array}{l}\text { Outcome } \\
\text { Variables }\end{array}$ & $\begin{array}{c}\text { Time of } \\
\text { Assessment }\end{array}$ & $\begin{array}{l}\text { Statistical } \\
\text { Test }\end{array}$ & Intervention & $\begin{array}{c}\text { Overall } \\
\text { Interpretation }\end{array}$ \\
\hline 1 & $\begin{array}{l}\text { Khairnar MR } \\
\text { et al. 2015 [7] }\end{array}$ & $\begin{array}{l}\text { In Vivo } \\
\text { study }\end{array}$ & $\begin{array}{l}50 \text { patien- } \\
\text { ts, } 18-20 \\
\text { years }\end{array}$ & $\begin{array}{c}\text { Antibacterial effica- } \\
\text { cy of } 0.2 \% \text { chlorhe- } \\
\text { xidine mouthwash } \\
\text { and } 0.6 \% \text { cranberry } \\
\text { mouthwash } \\
\text { against Streptococ- } \\
\text { cus mutans. }\end{array}$ & $\begin{array}{l}\text { At baseline and } \\
\text { after } 14 \text { days }\end{array}$ & $\begin{array}{l}\text { Paired t-test, } \\
\text { unpaired } \\
\text { t-test }\end{array}$ & $\begin{array}{l}\text { Group } 1-0.2 \% \text { chlorhe- } \\
\text { xidine mouthwash } \\
\text { Group } 2-0.6 \% \\
\text { cranberry mouthwash }\end{array}$ & $\begin{array}{c}\text { No statistically significant } \\
\text { difference between group 1and } \\
\text { group2 }\end{array}$ \\
\hline 2 & $\begin{array}{c}\text { Botelho MA } \\
\text { et al. 2009 } \\
\text { [28] }\end{array}$ & $\begin{array}{l}\text { In Vivo } \\
\text { study }\end{array}$ & $\begin{array}{l}55 \text { patien- } \\
\text { ts, } 18-69 \\
\text { years }\end{array}$ & $\begin{array}{l}\text { Antibacterial effect } \\
\text { of Essential oil } \\
\text { mouthwash and } \\
0.12 \% \text { chlorhexi- } \\
\text { dine mouthwash } \\
\text { against Streptococ- } \\
\text { cus mutans }\end{array}$ & $\begin{array}{l}\text { At baseline, after } \\
7 \text { days and } 30 \\
\text { days }\end{array}$ & $\begin{array}{l}\text { Fisher's exact } \\
\text { test and } \\
\text { Mann-Whit- } \\
\text { ney U-test, } \\
\text { Wilcoxon test }\end{array}$ & $\begin{array}{l}\text { Group 1-Essential oil } \\
\text { mouthwash, } \\
\text { Group 2- 0.12\% chlo- } \\
\text { rhexidine mouthwash, }\end{array}$ & $\begin{array}{l}\text { There was no difference in the } \\
\text { baseline colony count between } \\
\text { the } 2 \text { groups. Both the groups } \\
\text { showed similar effectiveness in } \\
\text { decreasing the salivary Strepto- } \\
\text { coccus mutans levels. }\end{array}$ \\
\hline 3 & $\begin{array}{l}\text { Srinagesh } \\
\text { J etal.2011 } \\
\text { [29] }\end{array}$ & $\begin{array}{l}\text { In Vivo } \\
\text { study }\end{array}$ & $\begin{array}{l}57 \text { patien- } \\
\text { ts, } 18-25 \\
\text { years }\end{array}$ & $\begin{array}{l}\text { Antibacterial effect } \\
\text { of } 6 \% \text { triphala } \\
\text { mouthwash and } \\
0.2 \% \text { chlorhexi- } \\
\text { dine mouthwash } \\
\text { against oral Strep- } \\
\text { tococcus mutans }\end{array}$ & $\begin{array}{l}\text { At baseline, after } \\
15 \text { days and } 45 \\
\text { days }\end{array}$ & $\begin{array}{l}\text { ANOVA, post } \\
\text { hoc test }\end{array}$ & $\begin{array}{c}\text { Group } 1-6 \% \text { triphala } \\
\text { mouthwash, } \\
\text { Group 2- } 0.2 \% \text { chlorhe- } \\
\text { xidine, } \\
\text { Gorup 3- No mou- } \\
\text { thwash }\end{array}$ & $\begin{array}{l}\text { There was no difference in the } \\
\text { baseline colony count between } \\
\text { the } 3 \text { groups; difference at } 15 \\
\text { days and } 45 \text { days was statisti- } \\
\text { cally significant. The difference } \\
\text { in the decrease in colony count } \\
\text { between group } 1 \text { and group } 2 \\
\text { was not statistically significant. } \\
\text { The difference between group } 1 \\
\text { and group } 3 \text {, group } 2 \text { and group } \\
3 \text { was highly significant. }\end{array}$ \\
\hline 4 & $\begin{array}{c}\text { Srinagesh } \\
\text { Jetal. 2012 } \\
{[30]}\end{array}$ & $\begin{array}{l}\text { In Vivo } \\
\text { study }\end{array}$ & $\begin{array}{l}60 \text { patien- } \\
\text { ts, } 18-25 \\
\text { years }\end{array}$ & $\begin{array}{l}\text { Antibacterial effect } \\
\text { of } 6 \% \text { triphala } \\
\text { mouthwash and } \\
0.2 \% \text { chlorhexi- } \\
\text { dine mouthwash } \\
\text { against oral Strep- } \\
\text { tococcus mutans }\end{array}$ & $\begin{array}{l}\text { At baseline, After } \\
48 \text { hours and } 7 \\
\text { days }\end{array}$ & $\begin{array}{l}\text { ANOVA, post } \\
\text { hoc test }\end{array}$ & $\begin{array}{c}\text { Group } 1-6 \% \text { triphala } \\
\text { mouthwash, } \\
\text { Group 2- } 0.2 \% \text { chlorhe- } \\
\text { xidine, } \\
\text { Gorup 3- plain water }\end{array}$ & $\begin{array}{l}\text { Reduction in colony count was } \\
\text { statistically significant between } \\
\text { group } 1 \text { and group } 3 \text { as well } \\
\text { as group } 2 \text { and group } 3 \text {. No } \\
\text { significant difference between } \\
\text { group } 1 \text { and group } 2 \text { at } 48 \text { hours } \\
\text { or } 7 \text { days. }\end{array}$ \\
\hline 5 & $\begin{array}{c}\text { Velmurugan } \\
\text { Aetal.2013 } \\
\text { [31] }\end{array}$ & $\begin{array}{l}\text { In Vivo } \\
\text { study }\end{array}$ & $\begin{array}{l}45 \mathrm{pa}- \\
\text { tients }\end{array}$ & $\begin{array}{l}\text { Antimicrobial } \\
\text { efficacy of } 20 \% \\
\text { aqueous extract of } \\
\text { Terminalia chebula, } \\
\text { Emblica officinalis } \\
\text { and chlorhexidine } \\
\text { mouthwash } \\
\text { against Streptococ- } \\
\text { cus mutansand } \\
\text { Lactobacilli. }\end{array}$ & $\begin{array}{l}\text { At baseline, } 10, \\
30,60 \text { and } 90 \\
\text { minutes }\end{array}$ & $\begin{array}{l}\text { One way ANO- } \\
\text { VA, Post-hoc } \\
\text { Tukey test. }\end{array}$ & $\begin{array}{c}\text { Group 1-20\% } \\
\text { aqueous extract of T. } \\
\text { chebula mouthwash } \\
\text { Group 2-20\% } \\
\text { aqueous extract of E. } \\
\text { officinalis mouthwash } \\
\text { Group 3-0.2\% chlo- } \\
\text { rhexidine mouthwash }\end{array}$ & $\begin{array}{l}\text { Group } 2 \text { showed highly signi- } \\
\text { ficant antimicrobial activity } \\
\text { compared with group } 3 \text { and } \\
\text { group 1against Streptococcus } \\
\text { mutans. Group } 3 \text { showed least } \\
\text { antimicrobial activity against } \\
\text { Streptococcus mutans when } \\
\text { compared with group1and } \\
\text { group 2. }\end{array}$ \\
\hline 6 & $\begin{array}{c}\text { Sam JE etal. } \\
\text { 2016 [32] }\end{array}$ & $\begin{array}{l}\text { In vivo } \\
\text { study }\end{array}$ & $\begin{array}{c}100 \\
\text { patients, } \\
18-22 \\
\text { years }\end{array}$ & $\begin{array}{l}\text { Antibacterial } \\
\text { efficacy of fluoride, } \\
\text { chlorhexidine, } \\
\text { herbal and xylitol } \\
\text { mouth washes } \\
\text { and pastes against } \\
\text { Streptococcus } \\
\text { mutans }\end{array}$ & $\begin{array}{l}\text { At baseline, } 1 \\
\text { month, } 3 \text { months } \\
\text { and } 6 \text { months. }\end{array}$ & $\begin{array}{l}\text { Post-hoc with } \\
\text { a bonferroni } \\
\text { test }\end{array}$ & $\begin{array}{l}\text { Group 1- fluoride tooth } \\
\text { paste and mouth wash } \\
\text { Group 2-chlorhexidine } \\
\text { tooth paste and mouth } \\
\text { wash } \\
\text { Group 3- herbal } \\
\text { tooth paste and } \\
\text { mouthwash( false } \\
\text { black, pepper, Indian } \\
\text { gum Arabic, neem,po- } \\
\text { megranate,triphala) } \\
\text { (Himalya complete } \\
\text { care) } \\
\text { Group 4-xylitol tooth } \\
\text { paste and mouthwash }\end{array}$ & $\begin{array}{l}\text { Group } 1 \text { showed a statistical sig- } \\
\text { nificant difference on S.mutans } \\
\text { when compared to the other } 3 \\
\text { groups at all time intervals. } \\
\text { Intergroup comparison showed } \\
\text { a significant reduction in group } \\
2 \text { followed by group } 1,3 \text { and } 4 \text {. }\end{array}$ \\
\hline
\end{tabular}




\begin{tabular}{|c|c|c|c|c|c|c|c|c|}
\hline S.No & $\begin{array}{l}\text { Author } \\
\text { \&Year }\end{array}$ & $\begin{array}{l}\text { Study } \\
\text { Type }\end{array}$ & $\begin{array}{l}\text { Study } \\
\text { Design }\end{array}$ & $\begin{array}{l}\text { Outcome } \\
\text { Variables }\end{array}$ & $\begin{array}{c}\text { Time of } \\
\text { Assessment }\end{array}$ & $\begin{array}{c}\text { Statistical } \\
\text { Test }\end{array}$ & Intervention & $\begin{array}{c}\text { Overall } \\
\text { Interpretation }\end{array}$ \\
\hline 7 & $\begin{array}{l}\text { Yadav M et al. } \\
2017 \text { [33] }\end{array}$ & $\begin{array}{l}\text { In Vivo } \\
\text { study }\end{array}$ & $\begin{array}{l}45 \text { patien- } \\
\text { ts, } 18-22 \\
\text { years }\end{array}$ & $\begin{array}{l}\text { Antibacterial } \\
\text { efficacy of green } \\
\text { coffee bean extract } \\
\text { and chlorhexidine } \\
\text { mouthwash } \\
\text { against Streptococ- } \\
\text { cus mutans }\end{array}$ & $\begin{array}{l}\text { At baseline and } \\
\text { after } 14 \text { days }\end{array}$ & $\begin{array}{l}\text { ANOVA and } \\
\text { Post-Hoc } \\
\text { Tukey }\end{array}$ & $\begin{array}{l}\text { Group 1- Green coffee } \\
\text { bean extract } \\
\text { Group } 2-0.2 \% \text { Chlo- } \\
\text { rhexidine }\end{array}$ & $\begin{array}{l}\text { No statistically significant } \\
\text { difference between group 1and } \\
\text { group 2.At baseline, no statisti- } \\
\text { cally significant difference for all } \\
3 \text { groups. Statistically significant } \\
\text { difference was observed for all } \\
3 \text { groups after } 14 \text { days. }\end{array}$ \\
\hline 8 & $\begin{array}{l}\text { Usha Cetal. } \\
2017 \text { [34] }\end{array}$ & $\begin{array}{l}\text { In vivo } \\
\text { study }\end{array}$ & $\begin{array}{l}46 \text { sub- } \\
\text { ject, } 18-25 \\
\text { yesrs }\end{array}$ & $\begin{array}{l}\text { Antibacterial effect } \\
\text { of } 0.12 \% \text { chlorhexi- } \\
\text { dine mouthwash } \\
\text { and } 0.5 \% \text { Stevia } \\
\text { mouthwash } \\
\text { against Streptococ- } \\
\text { cus mutans }\end{array}$ & $\begin{array}{c}\text { At baseline, after } \\
7 \text { days }\end{array}$ & $\begin{array}{l}\text { Wilcoxon } \\
\text { matched- } \\
\text {-pairs signe- } \\
\text { d-rank test } \\
\text { for intergroup } \\
\text { comparison, } \\
\text { Mann-Whit- } \\
\text { ney test for } \\
\text { intragroup } \\
\text { comparison. }\end{array}$ & $\begin{array}{l}\text { Group } 1-0.12 \% \text { chlo- } \\
\text { rhexidine } \\
\text { Group } 2-0.5 \% \text { Stevia } \\
\text { mouthwash }\end{array}$ & $\begin{array}{l}100 \% \text { reduction in microbial } \\
\text { colony count in group } 1 \text { and } \\
\text { group } 2 \text { after } 8 \text { th day. }\end{array}$ \\
\hline 9 & $\begin{array}{l}\text { Biria M etal. } \\
2017 \text { [35] }\end{array}$ & $\begin{array}{l}\text { In vivo } \\
\text { study }\end{array}$ & $\begin{array}{l}60 \text { patien- } \\
\text { ts, } 18-20 \\
\text { years }\end{array}$ & $\begin{array}{l}\text { Antibacterial effect } \\
\text { of pistacia lentiscus } \\
\text { extract tooth paste } \\
\text { and fluoride tooth } \\
\text { paste on Strepto- } \\
\text { coccus mutans }\end{array}$ & $\begin{array}{l}\text { Base line and } \\
\text { after a month }\end{array}$ & $\begin{array}{l}\text { Mann Whitney } \\
\text { Utest and } \\
\text { Wilcoxon test }\end{array}$ & $\begin{array}{c}\text { Group } 1(\mathrm{n}=30)- \\
\text { masdent tooth paste } \\
\text { (pistacia lentiscus } \\
\text { extract) } \\
\text { Group } 2(\mathrm{n}=30)-\text { - Crest } \\
\text { complete tooth paste } \\
\text { (Fluoride tooth paste) }\end{array}$ & $\begin{array}{l}\text { No statistical significant diffe- } \\
\text { rence in colony forming units at } \\
\text { base line and } 1 \text { month revalua- } \\
\text { tion also revealed a significant } \\
\text { reduction in colony forming } \\
\text { units, but the reduction was not } \\
\text { statistically significant. }\end{array}$ \\
\hline 10 & $\begin{array}{l}\text { Vinod KS et } \\
\text { al.2018 [36] }\end{array}$ & $\begin{array}{l}\text { In vivo } \\
\text { study }\end{array}$ & $\begin{array}{l}200 \\
\text { patients, } \\
18-22 \\
\text { years }\end{array}$ & $\begin{array}{l}\text { Antibacterial effect } \\
\text { of } 0.12 \% \text { chlorhe- } \\
\text { xidine } \\
\text { and Formulated } \\
\text { herbal mouthwash } \\
\text { (tulsi,neem,tri- } \\
\text { phala,turmeric) } \\
\text { on Streptococcus } \\
\text { mutans colony } \\
\text { forming units. }\end{array}$ & $\begin{array}{l}\text { Baseline and } \\
\text { after a month }\end{array}$ & $\begin{array}{l}\text { Paired test, } \\
\text { ANOVA, } \\
\text { followed by } \\
\text { Tukey's post } \\
\text { hoc test }\end{array}$ & $\begin{array}{l}\text { Group1( } \mathrm{n}=100)-0.12 \% \\
\text { chlorhexidine } \\
\text { Group2 }(\mathrm{n}=100) \text {-For- } \\
\text { mulated herbal mou- } \\
\text { thwash (tulsi,neem,tri- } \\
\text { phala,turmeric) }\end{array}$ & $\begin{array}{l}\text { There was a reduction in colony } \\
\text { forming units from baseline } \\
\text { to day } 7 \text { which was not statis- } \\
\text { tically significant in both the } \\
\text { groups and at } 14 \text { day there was } \\
\text { a significant reduction in CFU } \\
\text { counts, which was higher in } \\
\text { herbal group. }\end{array}$ \\
\hline 11 & $\begin{array}{l}\text { Jeddy N et al. } \\
2018 \text { [37] }\end{array}$ & $\begin{array}{l}\text { Invivo } \\
\text { study }\end{array}$ & $\begin{array}{l}60 \text { patien- } \\
\text { ts, } 18-24 \\
\text { years }\end{array}$ & $\begin{array}{l}\text { Antibacterial effect } \\
\text { of Dr.Dental care } \\
\text { liquid (red ginseng } \\
\text { extract, sweterica } \\
\text { japonica, camellia } \\
\text { sinensis, licorice), } \\
\text { colgate plax mouth } \\
\text { wash (cetylpyri- } \\
\text { dium chloride and } \\
\text { sodium fluoride), } \\
\text { Listerine mouth } \\
\text { wash, Rexidine } \\
\text { mouth wash (0.2\% } \\
\text { w/v chlorhexidine) } \\
\text { on Streptococcus } \\
\text { mutans }\end{array}$ & $\begin{array}{l}\text { Baseline and } \\
\text { after } 5 \text { days }\end{array}$ & $\begin{array}{l}\text { Wilcoxon } \\
\text { sign-rank test }\end{array}$ & $\begin{array}{l}\text { Group } 1(n=15)-\text { - } r . \\
\text { Dental care liquid } \\
\text { (red ginseng extract, } \\
\text { sweterica japonica, } \\
\text { camellia sinensis, } \\
\text { licorice) } \\
\text { Group 2 }(n=15) \text { - colga- } \\
\text { te plax mouth wash } \\
\text { (cetylpyridium chloride } \\
\text { and sodium fluoride) } \\
\text { Group 3 }(n=15) \text { - Listeri- } \\
\text { ne mouth wash } \\
\text { Group 4 ( } n=15)- \text { Rexidi- } \\
\text { ne mouth wash (0.2\% } \\
\text { w/v chlorhexidine) }\end{array}$ & $\begin{array}{l}\text { There was a statistical signi- } \\
\text { ficant reduction in the colony } \\
\text { forming units at } 5 \text { days as } \\
\text { compared with baseline. } \\
\text { At } 5 \text { day follow up, group I had } \\
\text { maximal reduction followed by } \\
\text { group II, III and IV. }\end{array}$ \\
\hline 12 & $\begin{array}{l}\text { Aparna M et } \\
\text { al. } 2018[38]\end{array}$ & $\begin{array}{l}\text { Invivo } \\
\text { study }\end{array}$ & $\begin{array}{c}75 \text { patien- } \\
\text { ts, } \\
18-30 \\
\text { years }\end{array}$ & $\begin{array}{l}\text { Antibacterial effect } \\
\text { of Licorice mouth } \\
\text { wash), triphala } \\
\text { mouth wash and } \\
\text { chlorhexidine } \\
\text { mouthwash }\end{array}$ & $\begin{array}{l}\text { Base line and } \\
\text { after 1 week }\end{array}$ & Anova test & $\begin{array}{l}\text { Group } 1(n=25) \text { - Licori- } \\
\text { ce mouth wash) } \\
\text { Group 2 }(n=25) \text { - tri- } \\
\text { phala mouth wash } \\
\text { Group 3 }(n=25) \text { - chlo- } \\
\text { rhexidine mouthwash }\end{array}$ & $\begin{array}{l}\text { Compared to the baseline, there } \\
\text { was a statistical significant re- } \\
\text { duction in colony forming units } \\
\text { at } 1 \text { week time interval. There } \\
\text { was no statistical significant } \\
\text { difference noted in all the three } \\
\text { groups at } 1 \text { week interval. }\end{array}$ \\
\hline
\end{tabular}


Table V - Results.

\begin{tabular}{|c|c|c|c|c|c|c|}
\hline \multirow{2}{*}{ S.No } & \multirow{2}{*}{$\begin{array}{l}\text { Author } \\
\text { \&Year }\end{array}$} & \multicolumn{2}{|c|}{ Materials used } & \multirow{2}{*}{$\begin{array}{l}\text { Method of } \\
\text { Evaluation }\end{array}$} & \multirow{2}{*}{ Mean values } & \multirow{2}{*}{ Outcome } \\
\hline & & $\begin{array}{l}\text { Conventional } \\
\text { product }\end{array}$ & Herbal product & & & \\
\hline 1 & $\begin{array}{c}\text { Khairnar MRetal. } \\
\text { 2015[7] }\end{array}$ & $\begin{array}{l}\text { Group 1:Chlorhe- } \\
\text { xidine }\end{array}$ & Group 2: Cranberry & $\begin{array}{l}\text { Quantitative analysis } \\
\text { using microbial cul- } \\
\text { ture method (Colony } \\
\text { forming units }\end{array}$ & $\begin{array}{l}\text { Group 1:69\% } \\
\text { Group 2:68\% }\end{array}$ & $\begin{array}{c}\text { No statistically } \\
\text { significant difference } \\
\text { between group 1and } \\
\text { group2 }\end{array}$ \\
\hline 2 & $\begin{array}{l}\text { Botelho MA } \\
\text { et al. } 2009 \text { [28] }\end{array}$ & $\begin{array}{l}\text { Group 2: Chlorhe- } \\
\text { xidine }\end{array}$ & Group 1: Lsidoides & $\begin{array}{l}\text { Quantitative analysis } \\
\text { using microbial cul- } \\
\text { ture method (Colony } \\
\text { forming units }\end{array}$ & $\begin{array}{l}\text { Group 1:58\% } \\
\text { Group 2:58\% }\end{array}$ & $\begin{array}{l}\text { No significant diffe- } \\
\text { rence between the } \\
\text { two groups. }\end{array}$ \\
\hline 3 & $\begin{array}{l}\text { Srinagesh J et al. } \\
\text { 2011[29] }\end{array}$ & $\begin{array}{l}\text { Group 2: Chlorhe- } \\
\text { xidine }\end{array}$ & $\begin{array}{l}\text { Group 1: 6\% triphala } \\
\text { Group 3: Passive } \\
\text { control group }\end{array}$ & $\begin{array}{l}\text { Quantitative analysis } \\
\text { using microbial cul- } \\
\text { ture method (Colony } \\
\text { forming units }\end{array}$ & $\begin{array}{l}\text { At } 15 \text { days } \\
\text { Group 1: 83\% } \\
\text { Group 2: } 80 \% \\
\text { Group 3:3\% } \\
\text { At 45 days } \\
\text { Group 1: } 67 \% \\
\text { Group 2: 65\% } \\
\text { Group 3:-7\% }\end{array}$ & $\begin{array}{l}\text { Group } 1 \text { and } 2 \text { differed } \\
\text { significantly from } \\
\text { control. No significant } \\
\text { difference between } \\
\text { group 1and group } 2 \text {. }\end{array}$ \\
\hline 4 & $\begin{array}{l}\text { Srinagesh J et al. } \\
2012 \text { [30] }\end{array}$ & $\begin{array}{l}\text { Group 2: Chlorhe- } \\
\text { xidine }\end{array}$ & $\begin{array}{l}\text { Group 1:6\% triphala } \\
\text { Group 3:Passive } \\
\text { control group }\end{array}$ & $\begin{array}{l}\text { Quantitative analysis } \\
\text { using microbial cul- } \\
\text { ture method (Colony } \\
\text { forming units }\end{array}$ & $\begin{array}{c}\text { At } 48 \mathrm{~h} \\
\text { Group 1: } 17 \% \\
\text { Group 2: } 14 \% \\
\text { Group 3:-6\% } \\
\text { At 7 days } \\
\text { Group 1: } 44 \% \\
\text { Group 2: } 45 \% \\
\text { Group 3:-2\% }\end{array}$ & $\begin{array}{l}\text { Group } 1 \text { and } 2 \text { differed } \\
\text { significantly from } \\
\text { control. No significant } \\
\text { difference between } \\
\text { group 1and group } 2 \text {. }\end{array}$ \\
\hline 5 & $\begin{array}{c}\text { Velmurugan A et al. } \\
\qquad 2013 \text { [31] }\end{array}$ & $\begin{array}{l}\text { Group 3: Chlorhe- } \\
\text { xidine }\end{array}$ & $\begin{array}{c}\text { Group 1:20\% } \\
\text { aqueous } \\
\text { extract of T.che- } \\
\text { bula Group 2: } 20 \% \\
\text { aqueous } \\
\text { extract of E. offici- } \\
\text { nalis }\end{array}$ & $\begin{array}{l}\text { Quantitative analysis } \\
\text { using microbial cul- } \\
\text { ture method (Colony } \\
\text { forming units }\end{array}$ & $\begin{array}{l}\text { Group 1:68\% } \\
\text { Group 2:78\% } \\
\text { Group 3:65\% }\end{array}$ & $\begin{array}{l}\text { Group } 2 \text { is signifi- } \\
\text { cantly better than } \\
\text { group 1and group } \\
\text { 3. Group } 2 \text { is signi- } \\
\text { ficantly better than } \\
\text { group 1and group } 3 \text {. }\end{array}$ \\
\hline 6 & $\begin{array}{c}\text { Sam JE etal. } 2016 \\
\text { [32] }\end{array}$ & $\begin{array}{c}\text { N0100 } \\
\text { Group 1 }(n=25)- \\
\text { fluoride tooth paste } \\
\text { and mouth wash } \\
\text { Group 2 }(n=25)- \\
\text { chlorhexidine tooth } \\
\text { paste and mouth } \\
\text { wash } \\
\text { Group } 4(n=25)-x y l i- \\
\text { tol tooth paste and } \\
\text { mouthwash }\end{array}$ & $\begin{array}{l}\text { Group } 3(\mathrm{n}=25)- \\
\text { herbal tooth paste } \\
\text { and mouthwash( } \\
\text { false black, pepper, } \\
\text { Indian gum Arabic, } \\
\text { neem,pomegrana- } \\
\text { te,triphala) (Himalya } \\
\text { complete care) }\end{array}$ & $\begin{array}{l}\text { Quantitative analysis } \\
\text { using microbial cul- } \\
\text { ture method (Colony } \\
\text { forming units) }\end{array}$ & 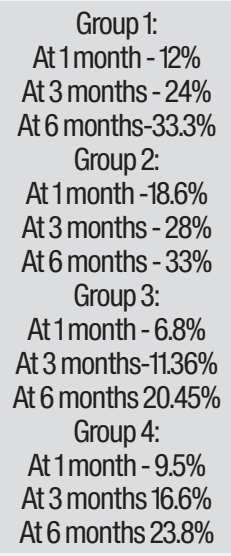 & $\begin{array}{c}\text { Statistical significant } \\
\text { difference was seen } \\
\text { in group } 1 \text { and } 2 \text { at } \\
\text { three different time } \\
\text { intervals. } \\
\text { There was no sig- } \\
\text { nificant difference } \\
\text { noted in group } 3 \text { and } \\
4 \text { at } 3 \text { different time } \\
\text { intervals. }\end{array}$ \\
\hline 7 & $\begin{array}{c}\text { Yadav M etal. } 2017 \\
\text { [33] }\end{array}$ & $\begin{array}{l}\text { Group 2: } 0.2 \% \text { chlo- } \\
\text { rhexidine }\end{array}$ & $\begin{array}{l}\text { Group 1: } 2 \% \text { Green } \\
\text { Coffee bean extract } \\
\text { Group 3: Sterile } \\
\text { water }\end{array}$ & $\begin{array}{l}\text { Quantitative analysis } \\
\text { using microbial cul- } \\
\text { ture method (Colony } \\
\text { forming units) }\end{array}$ & $\begin{array}{c}\text { Group } 1: 51 \pm 57 \\
\text { Group 2: } 55 \pm 27 \\
\text { Group } 3: 7 \pm 16\end{array}$ & $\begin{array}{l}\text { No significant diffe- } \\
\text { rence between two } \\
\text { groups but both the } \\
\text { groups were signifi- } \\
\text { cantly better than } \\
\text { group } 3\end{array}$ \\
\hline
\end{tabular}




\begin{tabular}{|c|c|c|c|c|c|c|}
\hline \multirow{2}{*}{ S.No } & \multirow{2}{*}{$\begin{array}{l}\text { Author } \\
\text { \&Year }\end{array}$} & \multicolumn{2}{|c|}{ Materials used } & \multirow{2}{*}{$\begin{array}{l}\text { Method of } \\
\text { Evaluation }\end{array}$} & \multirow{2}{*}{ Mean values } & \multirow{2}{*}{ Outcome } \\
\hline & & $\begin{array}{l}\text { Conventional } \\
\text { product }\end{array}$ & Herbal product & & & \\
\hline 8 & $\begin{array}{c}\text { Usha Cetal. } 2017 \\
\text { [34] }\end{array}$ & $\begin{array}{l}\text { Group 1:Chlorhe- } \\
\text { xidine }\end{array}$ & $\begin{array}{l}\text { Group 2: } 0.5 \% \text { Stevia } \\
\text { mouthwash }\end{array}$ & $\begin{array}{l}\text { Quantitative analysis } \\
\text { using microbial cul- } \\
\text { ture method (Colony } \\
\text { forming units }\end{array}$ & $\begin{array}{l}\text { Group 1: } 100 \% \\
\text { Group 2: } 100 \%\end{array}$ & $\begin{array}{c}\text { No statistically } \\
\text { significant difference } \\
\text { between group 1and } \\
\text { group2 }\end{array}$ \\
\hline 9 & $\begin{array}{c}\text { Biria M et al. } 2017 \\
\text { [35] }\end{array}$ & $\begin{array}{l}\text { Group } 2(n=30)- \\
\text { Crest complete tooth } \\
\text { paste (Fluoride tooth } \\
\text { paste) }\end{array}$ & $\begin{array}{l}\text { Group } 1(n=30) \text { - } \\
\text { masdent tooth paste } \\
\text { (pistacia lentiscus } \\
\text { extract) }\end{array}$ & $\begin{array}{l}\text { Quantitative analysis } \\
\text { using microbial cul- } \\
\text { ture method (Colony } \\
\text { forming units) }\end{array}$ & $\begin{array}{l}\text { Group 1:61.7\% } \\
\text { Group2: } \\
\text { 80.415\% }\end{array}$ & $\begin{array}{l}\text { No statistical sig- } \\
\text { nificant difference } \\
\text { between the two } \\
\text { groups. }\end{array}$ \\
\hline 10 & $\begin{array}{c}\text { Vinod KS et al. } 2018 \\
\text { [36] }\end{array}$ & $\begin{array}{l}\text { Group1(n=100)- } \\
0.12 \% \text { chlorhexidine }\end{array}$ & $\begin{array}{c}\text { Group } 2(n=100)- \\
\text { Formulated herbal } \\
\text { mouthwash (tulsi,- } \\
\text { neem,triphala,tur- } \\
\text { meric) }\end{array}$ & $\begin{array}{l}\text { Quantitative analysis } \\
\text { using microbial cul- } \\
\text { ture method (Colony } \\
\text { forming units) }\end{array}$ & $\begin{array}{c}\text { Group } 1: \\
\text { At day } 7-20.9 \% \\
\text { At day } 14-60.74 \% \\
\text { Group } 2: \\
\text { At day } 7-28.94 \% \\
\text { At day } 14-40.64\end{array}$ & $\begin{array}{l}\text { Compared to baseli- } \\
\text { ne values, statistical } \\
\text { significant difference } \\
\text { was seen in group } \\
2 \text { as compared to } \\
\text { group } 1 .\end{array}$ \\
\hline 11 & $\begin{array}{c}\text { Jeddy N et al. } 2018 \\
\text { [37] }\end{array}$ & $\begin{array}{c}\text { Group } 2 \text { ( } n=15) \text { - } \\
\text { colgate plax mouth } \\
\text { wash (cetylpyridium } \\
\text { chloride and sodium } \\
\text { fluoride) } \\
\text { Group } 3(n=15) \text { - Lis- } \\
\text { terine mouth wash } \\
\text { Group } 4 \text { ( } n=15) \text { - } \text { Rexi- } \\
\text { dine mouth wash } \\
\text { (0.2\% w/v chlorhe- } \\
\text { xidine) }\end{array}$ & $\begin{array}{l}\text { Group } 1(\mathrm{n}=15) \text { - } \mathrm{Dr} \text {. } \\
\text { Dental care liquid } \\
\text { (red ginseng extract, } \\
\text { sweterica japonica, } \\
\text { camellia sinensis, } \\
\text { licorice) }\end{array}$ & $\begin{array}{l}\text { Quantitative analysis } \\
\text { using microbial cul- } \\
\text { ture method (Colony } \\
\text { forming units) }\end{array}$ & $\begin{array}{c}\text { Group } 1: 69.94 \% \\
\text { Group 2: } 85.23 \% \\
\text { Group 3:70.2\% } \\
\text { Group 4:76.9\% }\end{array}$ & $\begin{array}{l}\text { Compared to base- } \\
\text { line values, group } 2 \\
\text { showed statistical } \\
\text { significant reduction } \\
\text { as compared to other } \\
\text { three groups. }\end{array}$ \\
\hline 12 & $\begin{array}{l}\text { Aparna M etal. } \\
2018 \text { [38] }\end{array}$ & $\begin{array}{l}\text { Group 3(n=25)- } \\
\text { chlorhexidine mou- } \\
\text { thwash }\end{array}$ & $\begin{array}{l}\text { Group } 1(n=25) \text { - Lico- } \\
\text { rice mouth wash) } \\
\text { Group } 2(n=25) \text { - tri- } \\
\text { phala mouth wash }\end{array}$ & $\begin{array}{l}\text { Quantitative analysis } \\
\text { using microbial cul- } \\
\text { ture method (Colony } \\
\text { forming units) }\end{array}$ & $\begin{array}{c}\text { At 7th day } \\
\text { Group 1: } 44.91 \% \\
\text { Group 2: } 45.85 \% \\
\text { Group } 3: 40.62 \%\end{array}$ & $\begin{array}{l}\text { No statistical signifi- } \\
\text { cant difference in all } \\
\text { the three groups. }\end{array}$ \\
\hline
\end{tabular}

\section{Individual Studies}

Study Characteristics \& Results of

Botelho MA et al. [28] evaluated and compared the antibacterial efficacy of an essential oil mouthwash comprising of L.sidoides with that of chlorhexidine. It was clearly shown that both the groups exerted a 58\% reduction in Streptococcus mutans count at the end of 7 days.

Two studies established the effect of Triphala on Streptococcus mutans by comparing its antibacterial efficacy with chlorhexidine. In a study conducted by Srinagesh $\mathrm{J}$ et al. (2011) [29], there was a significant reduction in the colony forming units of Streptococcus mutans in both Triphala (83\% and 67\%) and chlorhexidine (80\% and 65\%) at 15 and 45 days respectively in a sample of 57 people. In another study done by Srinagesh J et al. (2012) [30], a CFU reduction of $17 \%$ and $44 \%$ was found at 48 hours and 7 days respectively in Triphala group while a reduction of $16 \%$ and $45 \%$ was seen in chlorhexidine group in a total sample size of 60 subjects.

Velmurugan A et al. [31] have compared the antibacterial efficacy of Emblica officinalis, Terminalia chebula with chlorhexidine. The results projected a marked decrease in Streptococcus mutans in all the three groups i.e; $78.1 \%$ in E.officinalis group followed by $67.8 \%$ in T.Chebula group, and $65.0 \%$ in chlorhexidine group post 90 minutes of usage in a total sample size of 45 subjects. 
Sam JE et al. [32], have compared both the combined effect of both tooth pastes and mouthwashes together. The antibacterial efficacy of fluoride, chlorhexidine, (false black, pepper, Indian gum Arabic, neem, pomegranate, triphala) and xylitol. Fluoride group showed $12 \%, 24 \%, 33.3 \%$ reduction at 1,3 and 6 months intervals. Chlorhexidine group showed 18.6\%, $28 \%, 33 \%$ reduction at 1,3 and 6 months. Herbal group showed $6.8 \%, 11.36 \%, 20.45 \%$ reduction at 1, 3, 6 months. Xylitol group showed 9.5\%, $16.6 \%, 23.8 \%$ reduction at $1,3,6$ months, for a total sample of 100 subjects.

Usha C et al. [34], compared the anticariogenicity of Stevia rebaudiana with chlorhexidine and found 100\% Streptococcus mutans reduction in both the groups post 8 days of administration in a total sample of 46 .

In a clinical trial by Khairnar MA et al. [7], chlorhexidine was compared with cranberry and it was found that there were a $69 \%$ CFU reduction in chlorhexidine group and 68\% CFU reduction in cranberry group after 2 weeks in sample of 50 patients.

Yadav $\mathrm{M}$ et al. [33], compared green coffee bean extract with chlorhexidine and found 51.5 $\%$ Streptococcus mutans reduction in coffee group and $55.60 \%$ reduction in chlorhexidine group after 2 weeks in a sample of 45 subjects.

Biria M et al. [35], study compared pistacia lentiscus extract tooth paste with fluoride tooth paste. Fluoride group showed $80.415 \%$ reduction in streptococcus mutans levels at1month interval and pistacia group showed only $61.7 \%$ reduction at 1 month interval, in a sample of 60 .
Vinod KS et al. [36], study compared chlorhexidine with formulated herbal mouthwash (tulsi, neem, triphala, turmeric). chlorhexidine showed 20.94\%, 60.74\% at 7th and 14th day, herbal group showed 28.94\%, $40.64 \%$ at 7 th and 14 th days, in a sample of 100 .

Jeddy $\mathrm{N}$ et al. [37], study compared herbal mouth wash with combination of (red glistening extract, sweterica japonica, camellia sinensis, licorice), cetyl pyridium chloride and fluoride containing mouth wash, Listerine mouth wash and $0.2 \%$ chlorhexidine mouth wash. Herbal mouthwash showed $69.94 \%$ reduction of Streptococcus mutans at 5 days, cetylpyridium combined fluoride combination showed $85.23 \%$ reduction, Listerine showed $70.2 \%$ reduction and $0.2 \%$ chlorhexidine showed $76.9 \%$ reduction.

Aparna $\mathrm{M}$ et al. [38], study compared licorice, triphala and chlorhexidine mouthwashes. Licorice mouthwash showed $44.91 \%$, triphala showed $45.85 \%$, chlorhexidine showed $40.62 \%$ reduction in Streptococcus mutans at 7 th day.

When all the included studies were evaluated only two studies compared the effectiveness of herbal tooth pastes on Streptococcus mutans reduction [32,35]. Study by Biria M et al. [35], is the only study in literature search, which has evaluated the effectives of tooth paste alone without any adjunctive aid.

In all the studies compared, the reduction of Streptococcus mutans was almost insignificant or nearly approachable to conventional products (Table V, Table VI). 
Table VI - Summation Tables for Individual Parameters.

\begin{tabular}{|c|c|c|c|}
\hline Author & Year & Evaluation period & Outcome \\
\hline Khairnar MR etal. [7] & 2015 & Before treatment and after 14 days & No significant difference between two groups \\
\hline Botelho MA et al. [28] & 2009 & Before treatment and after 7 days & No significant difference between two groups \\
\hline Srinagesh J et al. [29] & 2011 & $\begin{array}{c}\text { Before treatment, at } 15 \text { days and at } 45 \\
\text { days }\end{array}$ & No significant difference between two groups \\
\hline Srinagesh J etal. [30] & 2012 & $\begin{array}{l}\text { Before treatment, after } 48 \text { hours and after } \\
\qquad 7 \text { days }\end{array}$ & No significant difference between two groups \\
\hline Velmurugan $A$ et al. [31] & 2013 & Before treatment and after treatment & Group 2 significantly better than group1and group 3 \\
\hline Sam JE etal.[32] & 2016 & Before treatment, after 3 and 6 months & $\begin{array}{l}\text { Statistical significant difference was seen in group } 1 \text { and } 2 \text { at } \\
\text { three different time intervals. } \\
\text { There was no significant difference noted in group } 3 \text { and } 4 \\
\text { at } 3 \text { different time intervals. }\end{array}$ \\
\hline Yadav M et al. [33] & 2017 & Before treatment and after 14 days & $\begin{array}{l}\text { No significant difference between two groups but both the } \\
\text { groups were significantly better than } \\
\text { group } 3\end{array}$ \\
\hline Usha Cetal.[34] & 2017 & Before treatment and 7 days & $\begin{array}{l}\text { No statistically significant difference between group 1and } \\
\text { group2 }\end{array}$ \\
\hline Biria M et al. [35] & 2017 & Before treatment and after a month & No statistical significant difference between the two groups. \\
\hline Vinod KS etal. [36] & 2018 & $\begin{array}{l}\text { Before treatment, at } 7 \text { th day and at } 14 \text { th } \\
\text { day }\end{array}$ & $\begin{array}{l}\text { Compared to baseline values, statistical significant differen- } \\
\text { ce was seen in group } 2 \text { as compared to group } 1 .\end{array}$ \\
\hline Jeddy N et al. [37] & 2018 & Before treatment and after 5 days. & $\begin{array}{l}\text { Compared to baseline values, group } 2 \text { showed statistical } \\
\text { significant reduction as compared to other three groups. }\end{array}$ \\
\hline Aparna M et al. [38] & 2018 & Before treatment and after 7 days & No statistical significant difference in all the three groups. \\
\hline
\end{tabular}

Table VII - Evidence Level of Selected Articles.

\begin{tabular}{|c|c|c|c|c|}
\hline S.N.O & Author & Year & Study Design & Level of Evidence \\
\hline 1 & Khairnar MR etal. [7] & 2015 & Randomized clinical trial & Level 2 \\
\hline 2 & Botelho MA et al. [28] & 2009 & Randomized clinical trial & Level 2 \\
\hline 3 & Srinagesh J et al. [29] & 2011 & Randomized clinical trial & Level 2 \\
\hline 4 & Srinagesh J et al. [30] & 2012 & Randomized clinical trial & Level 2 \\
\hline 5 & Velmurugan A etal. [31] & 2013 & Randomized clinical trial & Level 2 \\
\hline 6 & Sam JE et al.[32] & 2016 & Randomized clinical trial & Level 2 \\
\hline 7 & Usha C etal. [33] & 2017 & Randomized clinical trial & Level 2 \\
\hline 8 & Yadav M etal.[34] & 2017 & Randomized clinical trial & Level2 \\
\hline 9 & Biria M et al. [35] & 2017 & Randomized clinical trial & Level 2 \\
\hline 10 & Vinod KS et al. [36] & 2018 & Randomized clinical trial & Level 2 \\
\hline 11 & Jeddy N et al. [37] & 2018 & Randomized clinical trial & Level 2 \\
\hline 12 & Aparna M etal. [38] & 2018 & Randomized clinical trial & Level2 \\
\hline
\end{tabular}




\section{Studies}

Risk of Bias Within and Across the

The risk of bias for all the studies included in the present systematic review was assessed using Cochrane criteria (Table VIII), (Table IX). Four parameters were evaluated to assess the risk of bias on individual studies. Five out of twelve studies showed low risk of bias [7,28,29,30,31] and the remaining four showed moderate risk of bias $[33,34,35,36]$. Finally three included studies, showed high risk of bias $[32,37,38]$.

Low risk of bias was shown in the study conducted by Srinagesh J et al. 2011[32] as randomization, assessor blinding and dropouts or withdrawals if any, were well explained. Randomization and assessor blinding were done and well described in the trials reported by Khairnar MA et al. 2015,[7] Botelho MA et al. 2009,[28] Srinagesh J et al. 2012,[30] and Velmurugan A et al. 2013[31] also, there were no incidence of dropouts or withdrawals in the aforesaid clinical trials as well. Therefore, the five studies discussed above have low risk of bias.

Table VIII - Risk of BIAS - Major Criteria.

\begin{tabular}{|c|c|c|c|c|c|c|}
\hline S.No & Study & $\begin{array}{l}\text { Rando- } \\
\text { mization }\end{array}$ & $\begin{array}{l}\text { Allocation } \\
\text { Concealed }\end{array}$ & $\begin{array}{c}\text { Assessor } \\
\text { Blinding }\end{array}$ & $\begin{array}{l}\text { Dropouts } \\
\text { Described }\end{array}$ & $\begin{array}{c}\text { Risk } \\
\text { Of } \\
\text { Bias }\end{array}$ \\
\hline 1 & $\begin{array}{l}\text { Khairnar MRet } \\
\text { al. 2015 [7] }\end{array}$ & Yes & No & Yes & None & $\begin{array}{l}\text { Low } \\
\text { risk }\end{array}$ \\
\hline 2 & $\begin{array}{l}\text { Botelho MA et al. } \\
2009 \text { [28] }\end{array}$ & Yes & No & Yes & None & $\begin{array}{l}\text { Low } \\
\text { risk }\end{array}$ \\
\hline 3 & $\begin{array}{c}\text { Srinagesh } \\
\text { J etal.2011[29] }\end{array}$ & Yes & Unclear & Yes & Yes & $\begin{array}{l}\text { Low } \\
\text { risk }\end{array}$ \\
\hline 4 & $\begin{array}{c}\text { Srinagesh } \\
\text { Jetal.2012 [30] }\end{array}$ & Yes & No & Yes & None & $\begin{array}{l}\text { Low } \\
\text { risk }\end{array}$ \\
\hline 5 & $\begin{array}{l}\text { Velmurugan A } \\
\text { etal. 2013 [31] }\end{array}$ & Yes & No & Yes & None & $\begin{array}{l}\text { Low } \\
\text { risk }\end{array}$ \\
\hline 6 & $\begin{array}{l}\text { Sam JE etal. } \\
\text { 2015 [32] }\end{array}$ & Yes & Unclear & Unclear & None & $\begin{array}{l}\text { High } \\
\text { risk }\end{array}$ \\
\hline 7 & $\begin{array}{l}\text { Usha C etal. } \\
2017 \text { [33] }\end{array}$ & Yes & No & No & None & $\begin{array}{l}\text { Mo- } \\
\text { derate } \\
\text { risk }\end{array}$ \\
\hline 8 & $\begin{array}{l}\text { Yadav M etal. } \\
2017[34]\end{array}$ & Yes & No & Unclear & None & $\begin{array}{l}\text { Mo- } \\
\text { derate } \\
\text { risk }\end{array}$ \\
\hline 9 & $\begin{array}{c}\text { Biria M et al. } 2017 \\
\text { [35] }\end{array}$ & Yes & No & No & None & $\begin{array}{l}\text { Mo- } \\
\text { derate } \\
\text { risk }\end{array}$ \\
\hline 10 & $\begin{array}{l}\text { Vinod KS etal. } \\
2018 \text { [36] }\end{array}$ & Yes & No & Unclear & None & $\begin{array}{l}\text { Mo- } \\
\text { derate } \\
\text { risk }\end{array}$ \\
\hline 11 & $\begin{array}{l}\text { Jeddy N etal. } \\
2018 \text { [37] }\end{array}$ & Unclear & No & No & None & $\begin{array}{l}\text { High } \\
\text { risk }\end{array}$ \\
\hline 12 & $\begin{array}{c}\text { Aparna M etal. } \\
2018 \text { [38] }\end{array}$ & Unclear & Unclear & No & None & $\begin{array}{l}\text { High } \\
\text { risk }\end{array}$ \\
\hline
\end{tabular}

Table IX - Risk of Bias - Minor Criteria.

\begin{tabular}{|c|c|c|c|c|c|}
\hline S.No & Study & $\begin{array}{l}\text { Sample } \\
\text { Justified }\end{array}$ & $\begin{array}{c}\text { Baseline } \\
\text { Comparison }\end{array}$ & I/ECriteria & $\begin{array}{l}\text { Method } \\
\text { Error }\end{array}$ \\
\hline 1 & $\begin{array}{l}\text { Khairnar MR et al. } \\
\quad 2015[7]\end{array}$ & Yes & Yes & Yes & No \\
\hline 2 & $\begin{array}{l}\text { Botelho MA et al. } \\
2009[28]\end{array}$ & Yes & Yes & Yes & No \\
\hline 3 & $\begin{array}{l}\text { Srinagesh Jetal. } \\
\text { 2011 [29] }\end{array}$ & Yes & Yes & Yes & No \\
\hline 4 & $\begin{array}{l}\text { Srinagesh Jet al. } \\
2012[30]\end{array}$ & No & Yes & Yes & No \\
\hline 5 & $\begin{array}{l}\text { Velmurugan } \\
\text { Aet al. 2013 [31] }\end{array}$ & No & Yes & Yes & No \\
\hline 6 & Sam JEetal. 2016 [32] & No & Yes & Yes & No \\
\hline 7 & Usha Cetal.2017 [33] & No & Yes & Yes & No \\
\hline 8 & $\begin{array}{l}\text { Yadav M etal. } 2017 \\
\text { [34] }\end{array}$ & Yes & Yes & Yes & No \\
\hline 9 & Biria M et al. 2017 [35] & Yes & Yes & Yes & No \\
\hline 10 & $\begin{array}{l}\text { Vinod KS etal. } 2018 \\
{[36]}\end{array}$ & Yes & Yes & Yes & No \\
\hline 11 & Jeddy N et al. 2018 [37] & No & Yes & Yes & No \\
\hline 12 & $\begin{array}{l}\text { Aparna M etal. } 2018 \\
{[38]}\end{array}$ & No & Yes & Yes & No \\
\hline
\end{tabular}

Srinagesh J et al. 2011[29] described the limitations of their study emphasizing that only short-term effect of triphala was assessed against oral streptococci. Therefore more trials are required to explore long term antibacterial efficacy of triphala against various oral microorganisms. Yadav M et al. 2016[34] explained the limitations pertaining to small sample size and that more samples have to be incorporated in order to further validate the results.

Moderate risk of bias was seen in the studies conducted by Usha C et al. 2017,[33] Yadav M et al. 2016,[34] Biria M et al. 2017,[35] Vinod KS et al. 2018[36] as allocation concealment and assessor blinding was not done.

High risk of bias was shown in Sam JE et al. 2016,[32] Jeddy $N$ et al. 2018,[37] Aparna $\mathrm{M}$ et al. 2018,[38] studies as most of the things assessed were unclear.

Risk of bias of 5 studies- (Khairnar MR et al. 2015[7], Botelho MA et al. 2009,[28] Srinagesh $\mathrm{J}$ et al. 2011,[29] Srinagesh J et al. 2012,[30] Velmurugan A et al. 2013,[31]) had a low risk of bias, studies (Yadav M et al. 2016,[34] Usha C et al. 2017,[33] Biria M et al. 2017,[35] Vinod KS et al. 2018[36]) had a moderate risk of bias. 
Sam JE et al. 2016, Aparna M et al. 2018, Jeddy $\mathrm{N}$ et al. 2018 studies had high risk of bias.

\section{Analysis}

Synthesis of Results \& Additional

Meta-analysis was done for only five included studies [7,30,32,36,37]. Studies which provided the baseline \& post-analysis data (Mean \& S.D) were considered for Meta-analysis. Other seven studies [28,29,31,33,34,35,38] which analyzed the Streptococcus mutans count in terms of percentage reduction were considered for qualitative assessment.

\section{DISCUSSION}

\section{Summary of evidence}

The purpose of this review is to evaluate the antibacterial efficacy of natural products versus conventional products against Streptococcus mutans (Table I).

Literature has shown substantial evidence that; higher dental caries incidence was associated with infrequent tooth brushing than the counterpart [39]. Although brushing seems to be beneficial, it has no additional role in antibacterial activity or added beneficial anticariogenic activity, except for transient localized delivery of fluoride ions [40].

Hence, mouthwashes seemed to have an additional benefit in reducing the cariogenic plaque load, thereby enhancing the anticariogenic activity. Although, when mouthwashes are compared, most of the studies in the literature were concentrated on usage of chlorhexidine at different concentrations and it's considered to be a gold standard [41].

In the present systematic review too, most of the studies compared only the chlorhexidine at different concentrations ranging from 0.2 to 0.12 as a conventional product (Table IV, Table V).

As mentioned earlier, due to increasing threat of using antimicrobial agents leading to development of resistant microorganisms. The herbal trend is increased and various studies using animal and human tests, evaluated, these herbal compounds exhibiting antibacterial activity against various pathogens, anti-adhesive and inhibitory activity against the extracellular polysaccharide [42].

Among the various compounds evaluated, the polyphenolic compounds claimed to have maximal beneficial effect.

The natural products used in the studies compared were Essential oil, Triphala, Terminalia chebula, Emblica officinalis, Stevia rebaudiana, Cranberry, Green coffee bean, falseblack pepper, Indian gum arabic, neem, pomegranate, pistacia lentiscus extract, tulsi, turmeric,red glistening extract, sweterica japonica, camellia sinensis, and licorice (Table III, Table V). Upon

Report on Quality of Evidence Looked

Twelve trials were included in this review. All 12 studies included in this review have a level of evidence 2 (Table VII). Thus the level of evidence is high.

\section{META-ANALYSIS}

Only five [7,30,32,36,37] included studies were considered for meta-analysis. Meta-analysis was not possible for the studies interpreted the Streptococcus mutans reduction in terms of percentage reduction. A random-effects model was used for interpreting the data. The assessment for baseline and follow-up showed a significant reduction of Streptococcus mutans levels were seen at follow-up for both Herbal $\left(\mathrm{I}^{2}(\%)=\right.$ 95.688, $\left.\mathrm{H}^{2}=23.191, \mathrm{z}=1.9492, \mathrm{p}=0.051\right)$, (Figure 1) and conventional products ( $\mathrm{I}^{2}(\%)$ =94.315, $\left.\mathrm{H}^{2}=17.591, \mathrm{z}=2.0196, \mathrm{p}=0.043\right)$, (Figure 2). The overall estimated data indicated that, there was no difference in the herbal and conventional products on Streptococcus mutans reduction $\left(\mathrm{I}^{2}(\%)=7.0128, \mathrm{H}^{2}=1.0754, \mathrm{z}=\right.$ 0.7921, $\mathrm{p}=0.428$ ), (Figure 3 ). 
Figure 1 - Herbal baseline vs follow-up.

Forest plot

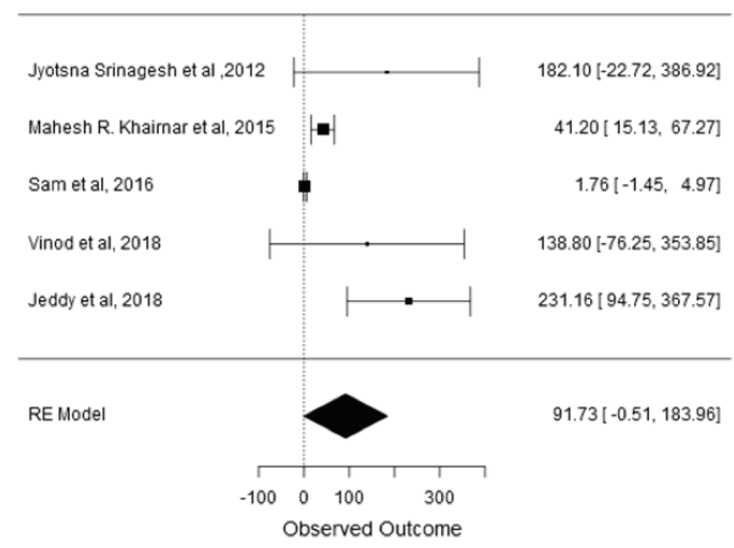

$\left(I^{2}(\%)=95.688, p=0.051\right)$

Figure 2 - Conventional baseline vs follow up.

\section{Forest plot}

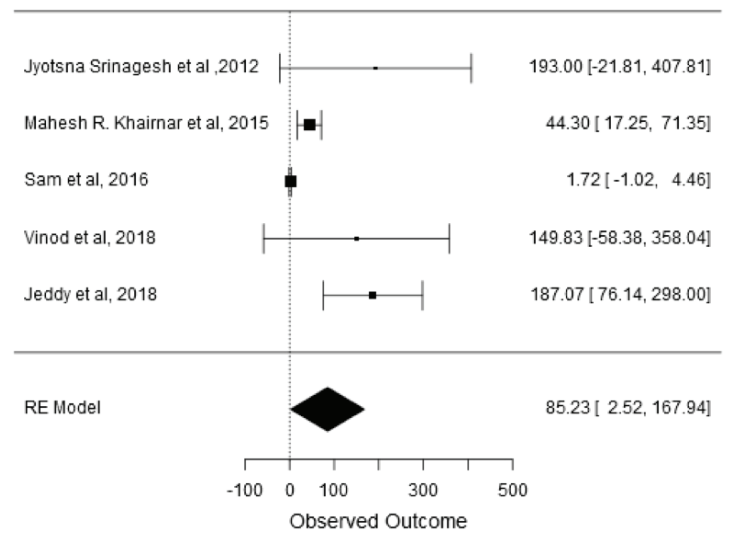

$\left(I^{2}(\%)=94.315, p=0.043\right)$

Figure 3 - Herbal vs conventional.

\section{Forest plot}

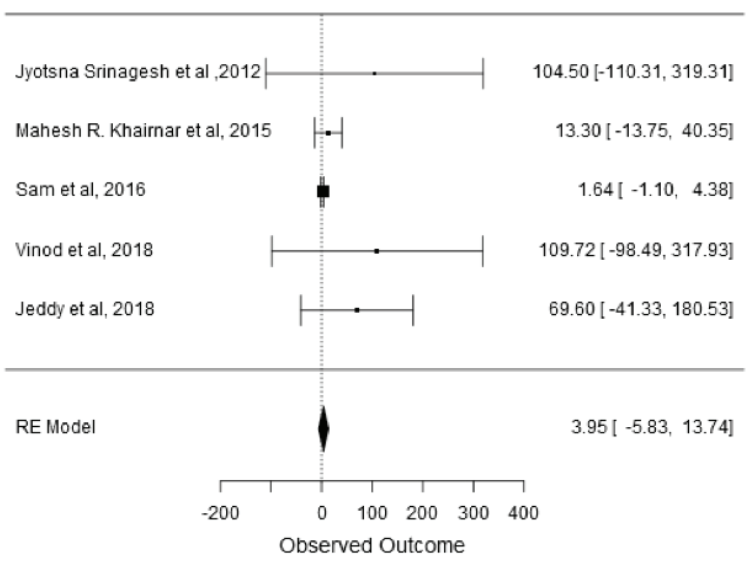

$\left(I^{2}(\%)=7.0128, p=0.428\right)$

\section{Inference}

From this systematic review it can be concluded that natural products can be used as an alternative to conventional products and proved to have a beneficial activity against Streptococcus mutans.

\section{Limitations}

Although, meta-analysis showed no significant difference between the conventional and herbal products on Streptococcus mutans reduction, the included studies were very less and most of them were of high risk. Most of the studies with high quality were not included for meta-analysis, as the data was provided in terms of percentage reduction. Studies included assessed only one pathogen and concentration was on antimicrobial reduction. But when dental caries is considered, it's multifactorial and various factors come into play to create a caries susceptible environment. None of the studies included concentrated on the caries index and susceptibility. The assessment was only based on the baseline microbial count. When critically appraised, studies concentrated mostly on different chlorhexidine for mutations and to a little extent of flouride combinations. Although, many other conventional agents proved to have a beneficial role, the dearth of studies concentrating on this aspect is low or almost nil. The assessments periods and follow up periods were also less to come to a specific conclusive remark.

\section{Future implications}

When the present review was considered, most of the research was concentrated on usage of mouth washes and the literature was scarce on comparing herbal versus conventional tooth pastes. When mouthwashes alone are considered, most of the studies compared and evaluated to chlorhexidine as a conventional product. None of the studies included a comparison on fluoride mouthwashes with the herbal products on re-mineralizing effect. It is a known fact that several herbal plant extracts have an additional re-mineralizing effect. So, it would be beneficial if future studies concentrate more on remineralizing mouthwashes. As a known fact, it 
is not always possible to achieve beneficial effect, with a single constituent. To combat the future antimicrobial agents, its better if future studies concentrate on the combination of plant extracts in obtaining the beneficial effect.

\section{CONCLUSION}

Herbal products were equally effective as conventional products in reducing Streptococcus mutans levels in adult population.

\section{FUNDING}

The present study was funded by Dr. Duddukuru Balaji, " Royal Pharmacy", 2244, Church Avenue, Brooklyn, NY, 11226, USA. We acknowledge them for the financial support.

Implications of Key Findings: The review revealed a unique perspective about the herbal agents which proved to be equally efficacious against Streptococcus mutans as conventional agents. This review highlighted the importance of herbal agents to combat the present antimicrobial resistance especially in relevance to oral pathogens.

\section{REFERENCES}

1. Longbottom CL, Huysmans MC, Pitts NB, Fontana M. Glossary of key terms. Monogr Oral Sci. 2009;21:209-216. doi:10.1159/000224225.

2. Marsh PD, Bradshaw DJ. Physiological approaches to the control of oral biofilms. Adv Dent Res. 1997;11(1):176-185. doi:10.1177/08959374970110010901 .PMID: 9524454

3. Hahn CL, Falkler WA Jr, Minah GE. Microbiological studies of carious dentine from human teeth with irreversible pulpitis. Arch Oral Biol. 1991;36(2):147-153. doi:10.1016/0003-9969(91)90077-8.PMID:2059163

4. Hamada S, Slade HD. Biology, immunology, and cariogenicity of Streptococcus mutans. Microbiol Rev. 1980;44(2):331-384. PMID:6446023

5. Bowen WH. Do we need to be concerned about dental caries in the coming millennium?.Crit Rev Oral Biol Med.2002;13(2):126-131. doi:10.1177/154411130201300203.PMID: 12097355

6. Gibbons RJ. Adherent interactions which may affect microbial ecology in the mouth. J DentRes. 1984;63(3):378-385. doi:10.1177/00220345840630030401 .PMID: 6583240

7. Khairnar MR, Karibasappa GN, Dodamani AS, Vishwakarma P,Naik RG, Deshmukh MA. Comparative assessment of Cranberry and Chlorhexidine mouthwash on streptococcal colonization among dental students: A randomized parallel clinical trial. Contemp Clin Dent. 2015;6(1):35-39. doi:10.4103/0976-237X.149289.
8. Allaker RP,Douglas CW. Novel anti-microbial therapies for dental plaquerelateddiseases. Int J Antimicrob Agents.2009;33(1):8-13. doi:10.1016/j. ijantimicag.2008.07.014.PMID: 18804350

9. Leibovici L,Paul M, Garner P,etal. Addressing resistance to antibiotics in systematic reviews of antibiotic interventions. J Antimicrob Chemother. 2016;71(9):2367-2369. doi:10.1093/jac/dkw135. PMID:27169438

10. Bell BG, Schellevis F, Stobberingh E, Goossens H, Pringle M. A systematic review and meta-analysis of the effects of antibiotic consumption on antibiotic resistance. BMC InfectDis. 2014;14:13. Published 2014 Jan 9. doi:10.1186/14712334-14-13.PMID:24405683

11. GummuluriS, Kavalipurapu VT, Kaligotla AV. Antimicrobial efficacy of Novel Ethanolic Extract of Morinda Citrifolia Against Enterococcus Feacalis by Agar Well Diffusion Method and Minimal Inhibitory Concentration- An Invitro Study. BrazDentSci 2019;22:365-70. doi:10.14295/bds.2018.v22i3.1731

12. Leach AJ, Leach DN, Leach GJ. Antibacterial activity of some medicinal plants of Papua New Guinea. Sci New Guinea. 1988 Jan; 14(1):1-7.

13. Aksoy A, Duran N, Toroglu S, Koksal F. Short-term effect of mastic gum on salivary concentrations of cariogenic bacteria in orthodontic patients. Angle Orthod. 2007;77(1):124-128. doi:10.2319/122205-455R.1PMID: 17029554

14. Campbell F.McDonald and Avery's Dentistry for the child and adolescent, 9th edition. Br Dent J 2011;210:191-191. https://doi.org/10.1038/sj.bdj.2011.135

15. Mohankumar KP,Priya NK, Madhushankari GS. Anti cariogenic efficacy of herbal and conventional tooth pastes - a comparative in-vitro study. J Int Oral Health. 2013;5(2):8-13.PMID:24155585

16. Chatterjee A, Debnath K, Rao NKH. A comparative evaluation of the efficacy of curcumin and chlorhexidine mouthrinses on clinical inflammatory parameters of gingivitis: A double-blinded randomized controlled clinical study. J Indian Soc Periodontol.2017;21(2):132-137.doi:10.4103/jisp.jisp_136_17PMID:29398858

17. Namiranian $\mathrm{H}$, Serino $\mathrm{G}$. The effect of a toothpaste containing aloe vera on established gingivitis. Swed Dent J. 2012;36(4):179-185. PMID:23421308

18. MegalaaN, Thirumurugan K, Kayalvizhi G, Sajeev R, Kayalvizhi EB, Ramesh $V$, Vargeese A. A comparative evaluation of the anticaries efficacy of herbal extracts (Tulsi and Black myrobalans) and sodium fluoride as mouthrinses in children: A randomized controlled trial. Indian J Dent Res. 2018 Nov 1;29(6):760. doi:10.4103/jidr.JJDR_790_16

19. Nayak SS, Ankola AV, Metgud SC, Bolmal U. Effectiveness of mouthrinse formulated from ethanol extract of Terminalia chebula fruit on salivary Streptococcus mutans among 12 to 15 year old school children of Belgaum city: A randomized field trial. J Indian Soc Pedod and Prev Dent. 2012 Jul 1;30(3):231. doi: 10.4103/0970-4388.105016

20. Agarwal P,Nagesh L.Comparative evaluation of efficacy of $0.2 \%$ Chlorhexidine, Listerine and Tulsi extract mouth rinses on salivary Streptococcus mutans count of high school children--RCT. Contemp Clin Trials. 2011;32(6):802-808. doi:10.1016/j.cct.2011.06.007.PMID:21763461

21. Hegde RJ, Kamath S. Comparison of the Streptococcus mutans and Lactobacillus colony count changes in saliva following chlorhexidine (0.12\%) mouth rinse, combination mouth rinse, and green tea extract $(0.5 \%)$ mouth rinse in children. J Indian Soc Pedod Prev Dent. 2017;35(2):150-155. doi:10.4103/ JISPPD.JISPPD_13_17.PMID:28492194

22. Yoshihara A, SakumaS, Kobayashi S, Miyazaki H. Antimicrobial effect of fluoride mouthrinse on mutans streptococci and lactobacilli in saliva. Pediatr Dent. 2001;23(2):113-117.PMID: 11340718

23. Malhotra N, Rao SP,Acharya S, Vasudev B. Comparative in vitro evaluation of efficacy of mouthrinses against Streptococcus mutans, Lactobacilli and Candida albicans. Oral Health Prev Dent. 2011;9(3):261-268.PMID:22068182

24. Kulkarni WV,Damle SG. Comparative evaluation of efficacy of sodium fluoride, 
chlorhexidine and triclosan mouth rinses in reducing the mutans streptococci count in saliva: an in vivo study. J Indian Soc Pedod Prev Dent. 2003;21(3):98104.PMID: 14703215

25. JauhariD, Srivastava N, Rana V, Chandna P.Comparative Evaluation of the Effects of Fluoride Mouthrinse, Herbal Mouthrinse and Oil Pulling on the Caries Activity and Streptococcus mutans Count using Oratest and Dentocult SM Strip Mutans Kit. Int J Clin Pediatr Dent. 2015;8(2):114-118. doi:10.5005/ jp-journals-10005-1295.PMID:26379378

26. Waly NG. Assessment of salivary Lactobacillus and Streptococcus mutans counts following sodium fluoride mouthrinsing in Egyptian children. Egypt Dent J. 1995;41(2):1179-1188.PMID:9497654

27. Ullsfoss BN, Ogaard B, Arends J, Ruben J, Röllla G, Afseth J. Effect of a combined chlorhexidine and $\mathrm{NaF}$ mouthrinse: an in vivo human caries model study.Scand J Dent Res. 1994;102(2):109-112. doi:10.1111/1.1600-0722.1994. tb01164.x.PMID: 8016555

28. Botelho MA, dos Santos RA, Martins JG, etal. Comparative effect of an essential oil mouthrinse on plaque, gingivitis and salivary Streptococcus mutans levels: a double blind randomized study. Phytother Res. 2009;23(9):1214-1219. doi:10.1002/ptr.2489.PMID: 19370543

29. Srinagesh J,Pushpanjali K. Assessment of antibacterial efficacy of triphala against mutans streptococci: a randomised control trial. Oral Health Prev Dent 2011;9(4):387-393.PMIID:22238738

30. Srinagesh J, Krishnappa P,Somanna SN. Antibacterial efficacy of triphala against oral streptococci: an in vivo study. Indian J Dent Res. 2012;23(5):696. doi:10.4103/0970-9290.107423.PMID:23422630

31. Velmurugan A, Madhubala MM, Bhavani S, Satheesh Kumar KS, Sathyanarayana SS, Gurucharan N. An in-vivo comparative evaluation of two herbal extracts Emblica officinalis and Terminalia Chebula with chlorhexidine as an anticaries agent: A preliminary study. J Conserv Dent. 2013:16(6):546549. doi:10.4103/0972-0707.120958.PMID:24347891

32. Sam JE, Benin P,Beaulah RH, Lnu G, Krishna LM, Raja JS. Comparative Evaluation of Antibacterial Efficacy of Four Toothpastes and Mouthwashes against Streptococcus mutans and Lactobacillus: An in vivo Study. Journal of Operative Dentistry and Endodontics 2016;1:60-5. doi:10.5005/JPJOURNALS-10047-0013.
33. Yadav M, Kaushik M, Roshni R, et al. Effect of Green Coffee Bean Extract on Streptococcus mutans Count: A Randomised Control Trial. J Clin Diagn Res. 2017;11(5):ZC68-ZC71. doi:10.7860/JCDR/2017/25743.9898.PMID:28658911

34. Usha C, Ramarao S, John BM, Babu ME. Anticariogenicity of Stevia rebaudiana extract when used as a mouthwash in high caries risk patients: Randomized controlled clinical trial. World. 2017 Sep;8(5):364-9. Doi:10.5005/ jp-journals-10015-1466.

35. BiriaM, Mohtavipour SS, Eslami G, Akbarzadeh Baghban A. Comparison of Effects of a Herbal Toothpaste with Crest Complete Toothpaste on Streptococcus Mutans and Lactobacillus of Saliva and Plaque Index: A Randomized Clinical Trial. Journal of Islamic Dental Association of Iran. 2017 Jan 10;29(1):29-35. http://dx.doi.org/10.30699/jidai.29.129.

36. Vinod KS, Sunil KS, Sethi P,Bandla RC, Singh S, Patel D. A novel herbal formulation versus chlorhexidine mouthwash in efficacy against oral microflora. Journal of International Society of Preventive \& Community Dentistry.2018 Mar;8(2):184. doi:10.4103/jispcd.JISPCD_59_18.

37. Jeddy N, Ravi S, Radhika T,Sai Lakshmi LJ. Comparison of the efficacy of herbal mouth rinse with commercially available mouth rinses: A clinical trial. J Oral Maxillofac Pathol. 2018;22(3):332-334. doi:10.4103/jomfp.JOMFP 30318 PMID:30651676

38. Aparna M. Evaluation of antimicrobial effectiveness of licorice and triphala mouthwashes against streptococcus mutans. J Ayurveda Holist Med JAHM 2018;6:26-33-33.

39. Kumar S, Tadakamadla J, Johnson NW. Effect of Toothbrushing Frequency on Incidence and Increment of Dental Caries: A Systematic Review and MetaAnalysis. J Dent Res. 2016;95(11):1230-1236. doi:10.1177/0022034516655315. PMID:27334438

40. Addy M. Plaque control as a scientific basis for the prevention of dental caries JRSoc Med. 1986;79 Suppl 14(Suppl 14):6-10.PMID:3543355

41. FigueroE, Nóbrega DF,García-Gargallo M, Tenuta LM, Herrera D, Carvalho JC. Mechanical and chemical plaque control in the simultaneous management of gingivitis and caries: a systematic review. J Clin Periodontol. 2017;44 Suppl 18:S116-S134. doi:10.1111/jcpe.12674.PMID:28266113

42. SprattDA, Daglia M, Papetti A, et al. Evaluation of plant and fungal extracts for their potential antigingivitis and anticaries activity. J Biomed Biotechnol. 2012:2012:510198. doi:10.1155/2012/510198.PMID:22500094

\section{Gummuluri Sri Ram}

(Corresponding address)

SVS Group of Institutions - SVS School of Pharmacy - Bheemaram, Hanumakonda -

Warangal - Telangana - India.

E-mail: ramchinna05@gmail.com

Date submitted: 2020 Jan 13

Accept submission: 2020 Jun 01 